Portland State University

PDXScholar

\title{
An Analysis of the Relationship Between the Degree of Maintained Fluency Improvement of Former Portland State University Stuttering Clients and the Overall Language Themes They Used
}

Karen F. Mathew

Portland State University

Follow this and additional works at: https://pdxscholar.library.pdx.edu/open_access_etds

Part of the Speech and Rhetorical Studies Commons, and the Speech Pathology and Audiology Commons

Let us know how access to this document benefits you.

\section{Recommended Citation}

Mathew, Karen F., "An Analysis of the Relationship Between the Degree of Maintained Fluency Improvement of Former Portland State University Stuttering Clients and the Overall Language Themes They Used" (1981). Dissertations and Theses. Paper 3063.

https://doi.org/10.15760/etd.3058

This Thesis is brought to you for free and open access. It has been accepted for inclusion in Dissertations and Theses by an authorized administrator of PDXScholar. Please contact us if we can make this document more accessible: pdxscholar@pdx.edu. 
AN ABSTRACT OF THE THESIS OF Karen F. Mathew for the Master of

Science in Speech Communication, with an emphas is in Speech Pathology/ Audiology, presented March 5, 1981.

Title: An Analysis of the Relationship between the Degree of Maintained Fluency Improvement of Former Portland State University Stuttering Clients and the Overall Language Themes They Used.

APPROVED BY MEMBERS OF THE THESIS COMMITTEE:

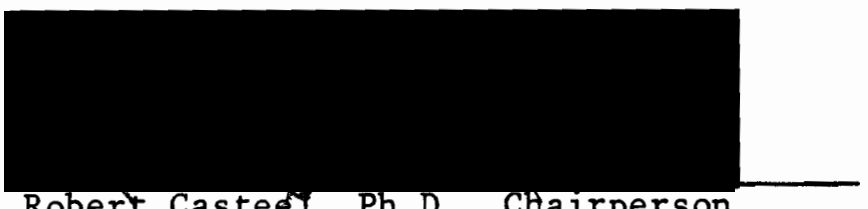

Robert Casteer, Ph.D., Chairperson

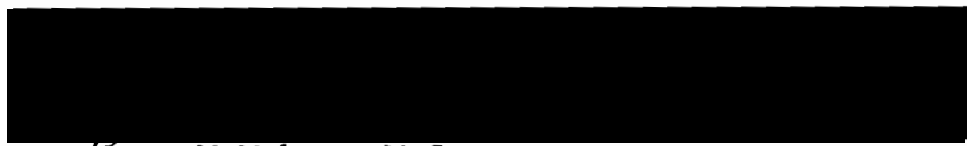

Joan McMahon, M.S.

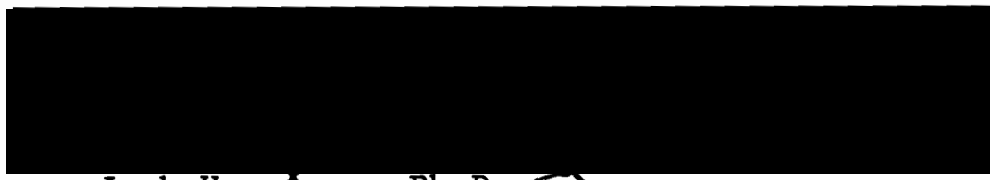

Jack Hegrenes, Ph.Dr

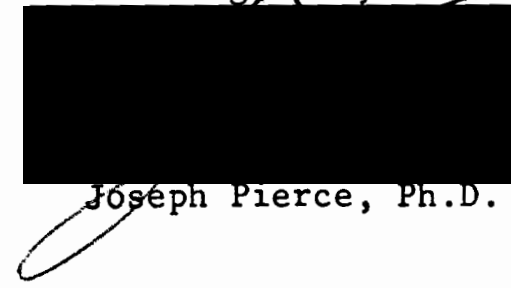

This research examined the relationship between the degree of maintained fluency improvement and the type of language used to respond to questions directly and indirectly related to speaking 
behavior. The subjects included sixteen former Portland State University stuttering clients who had participated in the Ginter (1979) study on fluency maintenance. The subjects responded to a thirteen item questionnaire dealing with themselves and their speaking behavior. Responses were recorded on the Modified Thematic Analysis Form developed by this examiner and analyzed according to guidelines set down by Stone and Casteel (1975) and this examiner.

Results of this research indicate that the degree of maintained fluency improvement as represented by overall clinical gains and by follow-up SSI scores (Ginter, 1979), correlates moderately with desirable language usage. This suggests, then, that greater gain and better SSI scores seem to be related to greater usage of overall desirable language themes.

The present research adds to that of others (Johnson, 1955; Williams, 1957; Shames, Egolf and Rhodes, 1969; Egolf, Shames and Blind, 1971; Prichard, 1971; Culatta and Rubin, 1973; and Casteel, 1976) who have found that there seems to be a relationship between fluency and language or thematics. While other research has indicated a relationship between the establishment of fluency and the use of desirable language during an intervention program, this research suggests that desirable language may also be related to overall clinical gain and fluency improvement that is maintained over an extended period of time. Results seem to indicate that those subjects who had farther to go to become fluent, thereby making greater gains overall and maintaining the greater gains over time, also talked more desirably about their speech. Reasons for the gains and maintenance of 
the gains may, in part, be related to the more desirable, realitybased language used by those subjects. 
AN ANALYSIS OF THE RELATIONSHIP BETWEEN THE DEGREE OF MAINTAINED

FLUENCY IMPROVEMENT OF FORMER PORTLAND STATE UNIVERSITY

STUTTERING CLIENTS AND THE OVERALL LANGUAGE

THEMES THEY USED

by

KAREN F. MATHEW

A thesis submitted in partial fulfillment of the requirements for the degree of

MASTER OF SCIENCE IN SPEECH COMMUNICATION

with an emphasis in

SPEECH PATHOLOGY/AUDIOLOGY

Portland State University

1981 
TO THE OFFICE OF GRADUATE STUDIES AND RESEARCH:

The members of the Committee approve the thesis of Karen F. Mathew presented March 5, 1981.
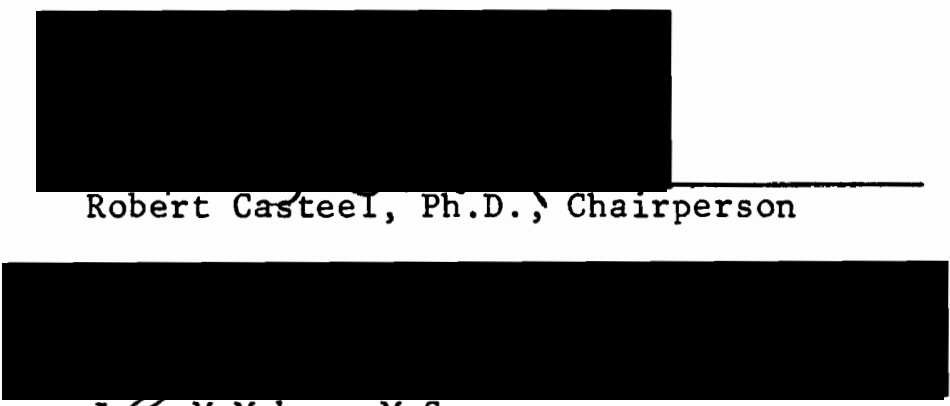

Jorn McMahon, M.S.

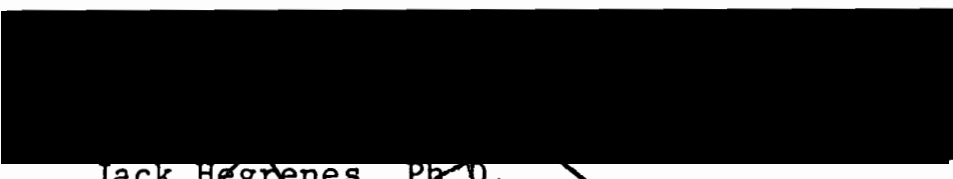

Jack Hegrenes, pr.D.

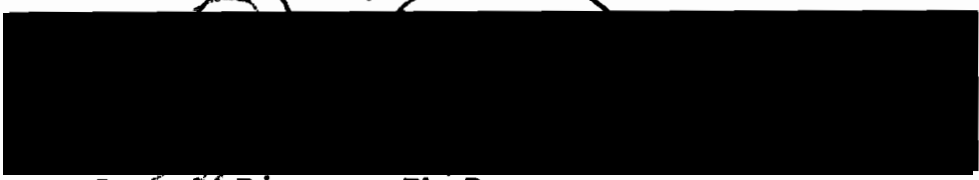

Joseph Pierce, Ph.D.

APPROVED :

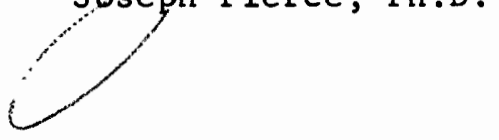

Ted Grove, Head, Department of Speech

Communication

Stanley E. Rauch, Dean, Graduate

Studies and Research 


\section{ACKNOWLEDGEMENTS}

Finally, I am ready to write my acknowledgements. Since there are really no rules and restrictions at this point, I thought this task would be an easy one. Not so. Where do I begin and how do I say thanks to all of the people who supported me through a longerthan-normal graduate program/thesis composition? We11, here goes.

Starting where it all began, I thank Dr. Robert Castee1, my thesis chairperson/director. If it had not been for Dr. Casteel and his enthusiastic presentation of materials in stuttering class, I may never have decided on a thesis topic at all. Thank you for all of your help.

To Joan McMahon, my advisor and helpful thesis committee member, I thank you for that extra push. When I was ready to "bag" the whole study, you helped me weigh the advantages and disadvantages of doing so. You listened and you gave. Thank you so much for your time and concern.

To Dr. Jack Hegrenes, a special thanks for your help with the statistical aspects of my study. Your suggestions were of great value. And most of a11, how can I ever thank you for the times you boosted my confidence and helped me to recognize the value of my study. Thank you.

To Dr. Joseph Pierce, I say again, sorry for the confusion regarding the time of my orals and again, thank you for caring enough to come on such short notice. I appreciate your contribution. 
To my friends at Portland State, especially to John Hanlan, Joan Polson, Carol Middleton and Sandy Neuburger, thank you. A special thanks goes to John and Carol for lending their expertise in the initial analysis of language responses for inter-judge reliability in this study; I couldn't have done it without you.

Also, to my friends at St. Francis Church, especially to the folk group, with whom I have spent many hours in rehearsal, in performance, in worship and at play, thank you. A special thanks to those who were empathetic and always encouraging: thank you Jim Mozena, Jerry Bier, Mary Jessen and Lori Skach.

A special thanks to my family: Dad, Mom, Sheila, John, Debbie, Terrie and Tammie. You've all been great. Thanks for not giving up on me. Dad and Mom, especially; what can I say? You have always been there when I needed you: growing up, going to school, working, going to school, graduating, getting married, and then, going to school again. Well, now I'm finally graduating (again). Your support, encouragement and care will help me to continue to grow and learn. Thank you for all that you have given.

Last of all, and probably most of all, to the person I've become very close to in the last five and one-half years, my husband, Frank. You knew when to encourage me to go on, when to leave me alone, when to ignore my ranting and raving and most of all, when to just be there. If I've ever forgotten to say thank you, I'm saying it now . . Thank You. 
TABLE OF CONTENTS

Page

ACKNOWLEDGEMENTS $\ldots \ldots \ldots$ ii

LIST OF TABLES . . . . . . . . . . . . . . . . vii vi

LIST OF FIGURES . . . . . . . . . . . . . . . viii

CHAPTER

I INTRODUCTION . . . . . . . . . . . . 1

Purpose ................ . . 5

Definition of Terms .......... 5

II REVIEW OF THE LITERATURE . . . . . . . . . 10

Responsibility and Fluency ......... 10

Relationship of Attitudes to Long-term

Improvement ............ 12

An Indicator of Awareness and Responsibility . . 12

Modification of Language Themes: Effects on

Stuttering Frequency . . . . . . . 15

Conclusions . . . . . . . . . . . 24

III METHODS . . . . . . . . . . . . 26

Subjects ............... . . 26

Instrumentation ........... 27

Data Collection ........... 30

Language Response Recording and Categorizing

Procedures .......... . 30

Reliability .............. 31 
CHAPTER

Data Analysis . . . . . . . . . . . .

IV RESULTS AND DISCUSSION . . . . . . . . . . . .

Results . . . . . . . . . . . . . .

Discussion . . . . . . . . . . . 38

V SUMMARY AND IMPLICATIONS . . . . . . . . . . . . 44

Sumnary . . . . . . . . . . . . . 44

Research Implications . . . . . . . . . 45

Clinical Implications . . . . . . . . . 47

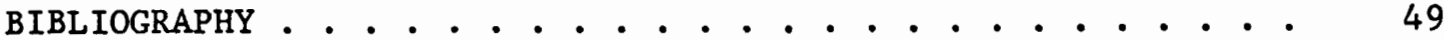

APPENDICES . . . . . . . . . . . . . . . . . . . 52

A QUESTIONNAIRE . . . . . . . . . . . . . . . 52

B THEMATIC ANALYSIS FORM . . . . . . . . . . 55

C MODIFIED THEMATIC ANALYSIS FORM . . . . . . . . . 56

D STUTTERING SEVERITY INSTRUMENT EVALUATION SCALE • • 57

E REVISED SEVERITY RATINGS FOR SSI, PORTLAND STATE UNIVERSITY . . . . . . . . 58

F LETTER OF INTENT . . . . . . . . . . . . . . . 59

G INFORMED CONSENT . . . . . . . . . . . . . . 60

H REMINDER POST CARD . . . . . . . . . . . . . 61

I THANK YOU POST CARD . . . . . . . . . . . . . 62

J SAMPLE : RESPONSE ANALYSIS . . . . . . . . . . 63

K GENERAL GUIDELINES FOR LANGUAGE RESPONSE ANALYSIS • 66

L WORD CUE GUIDELINES FOR PARAMETER ANALYSIS . . . . . 71

M COMPOSITE RESEARCH RESULTS . . . . . . . . . . 72

N SAMPLE QUESTIONNAIRE: PRE- AND POST-TEST MEASURE OF LANGUAGE USAGE . . . . . . . . . . 73 


\section{LIST OF TABLES}

TABLE

Page

I Spearman RHO Rankings for Clinical Gains and

Percentages of Overa11 Desirable Language

Response Usage . . . . . . . . . . . . . .

II Spearman RHO Rankings for Follow-up SSI Scores

and Percentages of Overall Desirable Language

Response Usage . . . . . . . . . . . . . . . 


\section{LIST OF FIGURES}

1 The mean number of interference responses per minute and the percentage of positive language responses in monologue and dialogue settings for baseline sessions and the videotaped sessions of conditioning, extinction and follow-up baseline . . . . . . 
CHAPTER I

\section{INTRODUCTION}

Historically, research in the area of stuttering (Van Riper, 1958; Freund, 1966; Prins, 1970; Ingham, Andrews and Winkler, 1972; Perkins, 1973; Fraser, 1974; Luper, 1974; Shames, 1975; Ainsworth, 1977; and Bloodstein, 1977) indicates a high rate of relapse among stutterers who underwent various treatment programs. After a brief period of fluency, one who stutters often reverts back to his old stuttering behaviors. As Bloodstein (1977) stated:

To speak fluently is such an easy accomplishment for most stutterers that they almost always seem just a short way from becoming normal speakers. Yet, once they have begun to speak normally they seem to be almost continually under the threat of imminent relapse.

This relapse, or failure to maintain fluency after contact with the clinician has been discontinued, was part of what Bar (1971) called the "mystery of stuttering."

Numerous opinions regarding the "mystery" of fluency failure have been advanced. One opinion, however, has become a focal point for many researchers. This point deals with actual responsibility for the speech behavior: Does the stutterer assume responsibility for his speech behavior, whether fluent or dysfluent? Several researchers (Williams, 1957; Kent, 1961; Rieber, 1965; Sander, 1970; Murphy, 1974; and Shames and Egolf, 1976) have reported that it is essential for the stuttering client, if he is to continue to be fluent 
after release from a program, to assume responsibility for all speech behavior. To assume this responsibility, he must be aware that it is what he does that influences how he speaks. Many, however, are unaware of their roles in the speaking process. They talk fluently when guided by their clinicians; but, on their own, they are unaware of how they actually talk, fluently and dysfluently. So, instead of assuming responsibility for their speech, they often attribute their dysfluent speech behavior to some mysterious "thing" lurking inside them; "it" is responsible for the way they talk.

When an individual is dysfluent, he may verbalize, "It got stuck." This language (thematics) is a medium through which the individual expresses his beliefs and attitudes about himself and his speech. According to Shames, Egolf and Rhodes (1969), what the stutterer says aloud about himself is often an extension of what he believes and feels about himself. These beliefs, in turn, are reflected in his social and speaking behavior. The thematics, or themes of communication a stutterer chooses to use to express his beliefs or attitudes, indicate "where he is" in terms of reality. Very often, what a stutterer believes about his speech is not in accordance with reality; the language he uses often reflects the lack of a realistic base. So, when a stutterer says, "It just happened. I don't know why. I tried to talk but 'it' got stuck in my throat," he is reflecting a lack of awareness and responsibility for his speech behavior; this type of language response denies reality. As long as a stutterer uses this type of language to express what he believes about himself and his speech, he fails to assume responsibility for 
changing his speech behavior.

The relationship between the stutterer's language responses to behavioral responsibility and fluency establishment has been speculated by several authors (Shames, Egolf and Rhodes, 1969; Sander, 1970; Egolf, Shames and B1ind, 1971; Prichard, 1971; Culatta and Rubin, 1973; and Casteel, 1976). Although descriptions vary from author to author, overall, language responses are either desirable or undesirable. Desirable language responses are indicative of responsibility and promote fluency; they are based in reality. Desirable language responses (DLR) may provide a physiological description of a behavior, stated actively and positively, indicate responsibility, express an optimistic attitude regarding speech, and/or reflect awareness of the speech behavior. Those responses that are considered undesirable reflect a lack of responsibility and are deemed detrimental to fluency; they indicate a denial or unawareness of reality. Undesirable language responses (ULR) may provide an obscure, superstitious description of a behavior, and may be stated passively and negatively, indicate lack of responsibility, express a pessimistic attitude regarding speech, and/or reflect ignorance of the speech behavior.

If language themes are somehow related to behavioral responsibility and fluency, as the above authors suggest, language themes should be considered when constructing a program to promote responsibility and to instate fluency. Via the language themes of responses, the individual's beliefs and attitudes become observable events that can be dealt with as target behaviors subject to modification. Through Thematic Modification, language themes conflicting with 
reality (ULR) can be replaced by those consistent with reality (DLR). When language themes reflect reality, attitudes and beliefs will also be more likely to reflect reality, thereby fostering behavioral responsibility and fluency.

In 1966, Casteel developed a behavior modification program for the treatment of stuttering. Since that time, it has evolved, addressing itself to both fluency and client language usage or thematics. While fluency is a major goal in each of the four stages of the program, modifying client thematics is equally critical. Prior to passage from Stage I to Stage II, and from Stage II to Stage III in Casteel's program, the client is required to speak fluently in a specified number of situations and to use desirable language responses when talking about his speech. In order to do this, he is also required to know and understand the anatomy and physiology of speaking. With these foundations, the client is on his way to assuming responsibility for his speech because he knows how and why he speaks a certain way. Fluency becomes an achievable goal.

Since the threat of relapse for individuals who stutter often seems "imminent," as Bloodstein (1977) stated, research is needed to help answer Why? relapse is so high. Thematic modification of the stuttering client's undesirable language (to a more desirable language) has been reported to promote the establishment of fluency in short term studies (Shames, Egolf and Rhodes, 1969; Egolf, Shames and Blind, 1971; and Culatta and Rubin, 1973). However, research has been meager so far.

At this time, the extent of the relationship between desirably modified language themes and long term, maintained fluency or fluency 
improvement is unknown. If there is a relationship between thematic modification and fluency or fluency improvement that is maintained over a longer period of time, one more piece of information may be added to solve the "mystery of stuttering" (Bar, 1971).

\section{Purpose}

The purpose of this study was to determine the relationship between the degree of maintained fluency improvement and the thematic content of language responses in those trained in fluency management through semantic reorientation. By way of amplification, the study was a follow-up investigation of the language usage of ex-clients who had successfully established fluent speech prior to dismissal and had participated in Ginter's (1979) maintenance study.

The essential question of this study was: What is the relationship between the degree of maintained fluency improvement and the type of language an individual uses to describe his speech?

\section{Definition of Terms}

For the purpose of this study, the following terms were defined as :

Casteel's Four Stage Stuttering Program: A behavior modification program for the treatment of stuttering which utilizes four stages in which specific vocal parameters are first sacrificed and then reinstated (Casteel and McMahon, 1978).

Desirable language responses (DLR): Language responses emitted by a person that are beneficial in gaining and maintaining "selfmonitored" fluent behavior. Four overlapping parameters that the 
responses reflect are discussed: Behavioral description of a response; this involves the use of descriptive, active and positive language components-- "I held my lips together too tightly and interfered with the air flow so I need to close my lips easier and then let go." Responsibility for speech behavior-- "I began to stop the air flow with my tongue as I was talking." or "I didn't let the air flow as I needed to." or "I made light contact with my tongue to my teeth." Optimistic attitude about speech performance-- "I like the way I am talking now; I really feel I have improved." Awareness of behavior, both incorrect and correct-- Knowledge of incorrect: "Even though I was aware of stopping the air, I didn't change my behavior." Knowledge of correct: "I am maintaining reduced tension in my laryngeal muscles" (Prichard, 1971; and Stone and Casteel, 1975).

Follow-up: The evaluation of an individual's behavior following termination of management (Ginter, 1979).

Maintenance (Carryover): According to Luper (1974), this involves ". . keeping the newly acquired behaviors going especially after contact with the clinician is discontinued."

Responsibility: According to Shames (1975), responsibility is the ". . process whereby the stutterer takes over and arranges for the occurrence of those events that previously had been arranged by the therapist."

Response unit: Phrase or sentence conveying a single thought. Self-maintenance: The final component of Casteel's Stuttering Program in which more dependence is placed upon the client's own ability to choose what he needs to do to talk fluently, with less dependence on the clinician (Casteel and McMahon, 1978). 
Stage I (Stretch and Flow): Stretch is prolonged speech; flow is exaggerated breathiness. Stage I is characterized by fluency, reduced rate, monotone, extreme breathiness and loose articulation. The end goal responses include (Casteel, 1976):

1. One hundred percent fluency while using Stretch and Flow in a clinic setting

2. Usage of desirable language responses regarding $\mathrm{d}$ interferences when the clinician provides the $\mathrm{S}$ and when the client's interferences serve as the

Stage II (Increased Breath): This stage is characterized by fluency, with normal rate reinstated; other parameters remain as in Stage I. The end goal responses include (Casteel, 1976):

1. One hundred percent fluency while using Increased Breath in the clinic setting

2. One hundred percent fluency while using Increased Breath in low stress situations outside the clinic

3. Usage of desirable language responses when the client's interferences serve as the $s^{d}$

Stage III (Reduced Breath): This stage is characterized by fluency, with normal rate maintained and loudness and pitch reinstated. A small amount of breathiness is still used as well as somewhat imprecise articulation. The end goal responses include (Castee 1,1976$):$

1. One hundred percent fluency while using Reduced Breath in the clinic setting

2. One hundred percent fluency while using Reduced Breath in medium and high stress situations outside the clinic

3. Usage of desirable language responses when describing fluency

Stage IV (Easy/Normal Talking): Rate, loudness, quality, pitch 
and articulation are all reinstated for effortless, normal talking. The end goal response is fluency while using this normal speech pattern (Castee1, 1976).

Stuttering Severity Instrument (SSI): Measurement tool used to score and determine the severity of stuttering in an individual speaker (Riley, 1972).

Thematic Analysis Form: A form designed to categorize thematic content of responses made by persons with functional voice disorders and other speech problems. The four categories analyzed include: description, responsibility, attitude and awareness (Stone and Casteel, 1975).

Thematics: Themes of communication, as exhibited by language usage, that reveal what a client believes about himself and his speech behavior (Stone and Casteel, 1975).

Transfer: The generalization of newly learned skills, in this case speaking, to daily routine and a variety of speaking situations (Casteel and McMahon, 1978).

Undesirable language responses (ULR): Language responses emitted by a person that are considered detrimental to the development of self-monitored and self-regulated fluent behavior. There are four overlapping parameters which the responses reflect: obscure description of a response; this involves obscurity of description as well as passive and negative components-- "I had a block." or "I had a slight interference." Lack of responsibility for speech-- "The word got stuck." or "It happened again." or "Once I begin stuttering, I can't stop." Pessimistic attitude about speech performance-- "I didn't do too we11." or "There are not many people I feel comfortable talking 
to so I don't practice much." A general lack of awareness of speech behavior, both incorrect and correct: Ignorance of incorrect: "I think I was too tense." Ignorance of correct: "I was so nervous I don't remember what I did to talk so fluently" (Prichard, 1971; and Stone and Casteel, 1975). 


\section{CHAPTER II}

\section{REVIEW OF THE LITERATURE}

Many researchers regard stuttering as a predominantly learned, hyperfunctional speech behavior (Johnson, 1957; Williams, 1957; Kent, 1961; Falck, 1969; Rubin and Culatta, 1971; Perkins, 19.73; Bloodstein, 1975; Brutten, 1975; Shames, 1975; and Castee1, 1976). If stuttering is a learned behavior, as some stated, it could be changed through the application of various principles of behavior modification (Whaley and Malott, 1971; Wischner, 1972; and Shames and Egolf, 1976). The stutterer learns to be a fluent speaker as various contingencies and consequences are controlled within the clinic. Since it is hoped transfer and maintenance of fluent speech behavior will go beyond the four walls of the clinic room, the client needs to learn to be his own clinician, responsible for maintaining his fluent behavior.

\section{Responsibility and Fluency}

It is believed by many that, in order to accomplish this feat of transfer and maintenance to the "real" world, awareness of and self-responsibility for speech behavior must be considered as critical components in the early stages of any fluency program (Johnson, 1955; Williams, 1957; Shames, Egolf and Rhodes, 1969; Sander, 1970; Rubin and Culatta, 1971; Perkins, 1973; and Castee1, 1976). When a 
client fails to accept the responsibility for his speech, he usually relies on the clinician for continued support. This is not practical in the "real" world. According to Shames (1975), selfresponsibility

- . becomes a most vital response class for the stutterer when he reaches that point in therapy when external controls of his behavior by the therapist are to be replaced by or combined with his own selfevaluations and self-generated contingencies.

Although many agreed that self-responsibility is a critical goal in a fluency program, they also agreed that it is often a difficult one to achieve due to the stuttering client's often unrealistic, unverifiable attitudes and beliefs about himself as a speaker. The client often attributes his dysfluent speech behavior to a mysterious "something" within him which emits the behavior; he fails to assume responsibility for the behavior. Williams (1957) blamed the evolution of this mythical belief on earlier research done in the area of stuttering. Much of past research posited that there was something physiologically or psychologically different about a person who stutters; there was something in the stutterer's body or mind that made him stutter. This "it" was the source of all the trouble. Therefore, the person who stuttered was in no way responsible for his abnormal speech behavior. Although Williams (1957) and many other advocates of learning theory have spoken to the contrary, old views have persisted, excusing the stutterer from accepting responsibility for his stuttering and from changing his speech behavior. 


\section{Relationship of Attitudes to Long-term Improvement}

As stated before, the client's attitudes and beliefs about his speech and himself as a speaker guide him to either accept or deny responsibility for his behavior and as a result, talk fluently or dysfluently. Based on the original Cutler study (1973), Andrews and Cutler (1974) suggested that failure of subjects to normalize attitudes may affect long-term maintenance of fluent behavior. However, no conclusive data were provided.

Another study, conducted by Guitar (1976) indicated there may be a relationship between the attitudes of stutterers and their longterm improvement. In the study, even though all subjects terminated the treatment program fluent, those measured as having more negative attitudes prior to treatment demonstrated a higher level of stuttering a year later than others.

\section{An Indicator of Awareness and Responsibility}

Studies have indicated that attitudes and beliefs seem to influence long-term speech improvement. Numerous researchers have investigated the language stutterers use to express these attitudes and beliefs.

Johnson (1942) suggested that the assumptions, or attitudes and beliefs that a stutterer has regarding normal speech and stuttering may be, in varying degrees, conducive to stuttering behavior. Johnson's $(1946,1955)$ semantic hypothesis provided the initial impetus for studying these assumptions. He suggested that stuttering is largely a semantic disorder. Since the semantic environment of the 
stutterer, according to Johnson, is important to the perpetuation of the stuttering behavior, he therefore explored how the stutterer viewed himself as a speaker by analyzing the semantics of his. Ianguage themes. He found that the stutterer used predominantly obscure, often unverifiable terms rather than descriptive, realitybound terms. According to Johnson (1946), ". . the problems of knowing and of understanding center around the relation of language and reality. . . " With regard to the person who stutters, Johnson explained that the stutterer's habitual use of obscure, nondescriptive terms such as "it" or "this thing" stifles a true awareness of his speech behavior. With these terms, the person who stutters is not reflecting any real knowledge of the variables that are responsible for his stuttering behavior and thereby is not likely to take the first step toward better adjustment and responsibility necessary to change his behavior.

Frasier (1955) also studied the thematics of the language used by those who stutter. Nineteen people who exhibited stuttering behaviors were chosen to respond to questions regarding theories about their own stuttering. The language they used to respond to such questions was noted. Some examples of their responses included: "My stuttering is inside me and won't come out." and "I believe the main causes are self-consciousness and lack of self-control." According to Frasier, this type of language, vague, unverifiable and lacking in detail, was common. This author added, "Therefore, in using this vague language the stutterer says little which would help us or him to gain a better understanding of his problem." 
Williams (1957) was supportive of Johnson's semantic theory of stuttering and went on to elaborate. Based on clinical impression and judgement, Williams hypothesized that many of the difficulties experienced by stutterers arise from their thoughts about stuttering and their reactions to those thoughts. Egolf, Shames and Blind

(1971) provided a good description of this.

If the stutterer regards stuttering as some vague, undefinable entity that just happens, he is unable to descriptively analyze his own behavior and such an analysis is prerequisite to making specific behavioral changes.

It appears, then, that stuttering behavior may be maintained to a great degree by the very concepts or attitudes and beliefs a stutterer possesses as revealed by his language responses.

More recent research has yielded similar findings. Rhodes, Shames and Egolf (1971) expressed:

. . if a stutterer's perceptions as revealed by his language include himself as the victim of events beyond his control and his stuttering as "it" or "this thing," he is not reflecting any knowledge of the variables responsible for his behavior (of why he talks the way he does), and is not likely to change that behavior.

In summary, numerous authors have agreed that many people who stutter exhibit misperceptions about why they talk the way they do. These misperceptions dictate the vague language they use; the vague language they use, in turn, fuels their misperceptions. This vicious circle continues and the stutterer does not change his behavior. The need for semantic reorganization is evident. The reason for this is we1l stated by Stone and Casteel (1975): "A basic premise of general semantics is that a person better understands reality if language 
usage conforms to reality."

\section{Modification of Language Themes: Effects on \\ Stuttering Frequency}

Upon analysis of the stuttering client's language themes, researchers noted vague responses, indicative of a poor understanding of the behavior known as stuttering and a denial of responsibility for speech behavior in general. Due to an hypothesized relationship of language themes to stuttering frequency (Johnson, 1955; Williams, 1957; and Shames, Egolf and Rhodes, 1969), the need for a more formal investigation into thematic modification and the effect it has on stuttering has become apparent. Some structured programs incorporating various approaches of thematic modification have been developed and studied.

Based on the assumption that there is a relationship between language usage and stuttering, Shames, Egolf and Rhodes (1969) deve1oped three experimental Thematic Content Modification Programs aimed at modifying language themes the stutterer uses to talk about himself and his speech. Each program varied slightly in terms of client appropriateness, the target response and the clinician's behavior to the response. Based on thematic content, client responses were classified as positive or negative. For example, responses were classified as positive if they reflected the client's awareness of events accompanying his stuttering behavior, a clear description of his overt struggle and/or avoidance behavior, positive and negative affect statements which described or evaluated his feelings and finally, if they reflected contemplated or completed action. 
Responses were considered to be negative if they were vague, imprecise and nondescriptive when referring to normal speech and stuttering. Another type of negative response reflected the client's perception of himself as a helpless victim of events for which he had no control. Positive language responses were considered desirable and beneficial to "therapeutic progress"; negative responses were deemed undesirable and incompatible with recovery from stuttering.

In the initial study (Shames, Egolf and Rhodes, 1969), a trained interviewer conducted a preliminary interview, only interacting verbally when necessary, to encourage output. Based on the responses emitted in the interview and in a fifty minute monologue, the baselines were determined and the subjects were placed in one of the three Thematic Content Modification Programs. All three programs were designed to strengthen positive, desirable responses. In general, the results for all three types of programs indicated an increase in the positive responses and a decrease in the negative ones. Also, even though no direct action was taken to modify the actual stuttering behavior, there was a concurrent decrease in the frequency of stuttering. Although some results were generated, the authors caution that the data were inconclusive since the subjects involved were still in the process of clinical intervention. They concluded, stating tentatively:

The frequency of stuttering and the thematic content observed in the utterances of stutterers appear to covary in the data collected thus far. This co-variation supports the hypothesis that the thematic content of stutterers' language is related to stuttering behavior. Thus it may be that the content of stutterers' language, to a major degree, controls and maintains stuttering behavior. 
A later study conducted by Egolf, Shames and Blind (1971) involved the treatment of a forty-seven year old female who stuttered. The treatment program developed for her included three stages. The first stage involved the manipulation and modification of certain overt stuttering behaviors. The second stage focused on changing the client's perceptions about her stuttering and herself. Finally, the last stage encouraged the client to engage in various speaking and social situations. By the end of the first stage, the client maintained eye contact and verbal output and reduced her stuttering behavior. Since the client viewed her stuttering as some mysterious affliction visited upon her, the second stage of treatment incorporated Thematic Content Modification. During each forty-minute session of this stage of treatment, the client talked while the clinician reacted with verbal approval to any positive language response made by the client and with verbal disapproval to any negative response. The second stage included twenty-four sessions of intervention. During this time, stuttering frequency and severity decreased. The client also was using a greater number of positive statements than negative ones. The authors' interpretation of the statements revealed that the client was able, by the end of the second stage, to reliably describe her stuttering in terms of what she did to talk. However, the authors also noted the client still felt "helpless" in changing her behavior outside the clinic. Her feeling of helplessness was reflected in many negative statements beginning with the phrase "I can't." Due to the pervasive fear of outside speaking situations, a third stage of treatment was constructed to reduce her 
avoidance behavior and increase her approach behavior and thereby stimulate transfer of fluency to outside situations. During the fifteen sessions of this stage three, both stuttering frequency and severity decreased. The client also increased her usage of positive responses. At this time, the client had made some gains in speech and had reported an outside incident which seemed indicative of success. For these reasons and due to the client's request, discharge was agreed upon. Shortly after discharge, re-evaluation of the client showed that she had maintained the gains made in treatment and had improved somewhat beyond. Six months post-intervention, a second reevaluation was conducted during which the client was completely fluent. Prior to the second re-evaluation, the client had achieved other significant goals that may or may not have influenced her success in speaking, i.e., she received her high school diploma and passed her test for a driver's license.

In 1966, Casteel developed a behavior modification program for the treatment of stuttering. Since that time, numerous revisions have been made. Implications of the program (1976) are that stuttering is a learned behavior involving hypertensive muscle action and incorrect choices. The incorrect choices an individual makes stem from his lack of awareness regarding the physiological aspects of fluency and stuttering. Historically, the individual has not assumed the responsibility for choosing his speech behavior. The program postulates that, rather than learning to be an efficient stutterer, the individual is capable of learning to be an efficient talker. In order to promote fluency, awareness and responsibility, 
Casteel's program addresses the modification of speaking behavior as we11 as the modification of language usage or thematics. Fluency is a goal for each of the four stages of Casteel's program. In addition to fluency, prior to passage from Stage I to Stage II, and from Stage II to Stage III, the client is required to use desirable language responses to describe his speech. In part, desirable language includes what Sander (1970) calls descriptive, active and positive language. With this language, the client can behaviorally describe what he is doing to talk, whether fluently or dysfluently. This type of behavioral description requires the client to know the physiological processes of speech so he understands what he is doing physiologically when he is fluent and when he is dysfluent. An example of a statement that illustrates three conditions (Descriptive-ActivePositive) of desirable language is: "I held my lips together too tightly so I should close them easier and then let go." First of aIl, according to Casteel and McMahon (1978), the statement behaviorally describes what resulted in interruption of air flow. It also indicates active acceptance of responsibility for the behavior. Finally, it emphasizes the positive, stating what to do rather than what not to do. It is believed that if the individual understands and uses behaviorally desirable language conforming to reality, he will then better understand reality and be more likely to assume responsibility for his behaviors, both within and outside of a clinical situation. He is aware of what he is doing and when he is doing something; he is aware of what he needs to do or what choice he needs to make. Stone and Casteel (1975) describe awareness as "basic to 
self-directed behavior" and this awareness provides an answer to the question: "What do I need to do to change my stuttering behavior to fluent speech?"

Using Casteel's program, Prichard (1971) conducted a study in which the program was administered to a thirty-five year old male subject. Following three baseline sessions of thirty minutes each, the conditioning program was begun; this totaled twenty-two hours and lasted for a period of eight weeks (three sessions/week). Four weeks after completion of the conditioning phase, a follow-up baseline was determined.

Two of the goals of the conditioning phase included developing a consistently "self-monitored normal fluent speech" during reading, monologue and dialogue and increasing the percentage of "selfmonitored" positive (desirable) language responses while reducing the percentage of negative (undesirable) responses. Following the conditioning phase, the frequency of stuttering behavior in each of the three mediums decreased significantly from the baseline levels: from $20.00-0.00$ in reading, from $22.39-.79$ in monologue and from $23.15-1.33$ in dialogue. Also, the subject increased his use of positive (desirable) language from 30 percent at baseline to approximately 95 percent at the completion of conditioning and reduced his use of negative (undesirable) language from 70 percent at baseline to 5 percent at the end of conditioning.

At follow-up four weeks later certain changes were notable. For reading, the frequency of stuttering behavior was the same at follow-up as at the end of conditioning (extinction), 0.00. For mono- 
logue, follow up showed an increase in stuttering frequency from .79 at the end of conditioning to .95. During dialogue, stuttering frequency increased from 1.33 at the end of conditioning to 2.59 at follow-up. Language response types showed a similar shift from the end of conditioning to follow-up. The percentage of positive (desirable) language responses decreased slightly from approximately 95 percent to approximately 87 percent while the percentage of negative (undesirable) language responses increased from approximately 5 percent to 11 percent.

Figure 1 displays the rate of stuttering and the percentage of desirable language responses with respect to the tracking periods in Prichard's study: Baseline, Conditioning, Extinction and Follow-up Baseline. The findings suggest a possible relationship between stuttering frequency and language responses. During conditioning, para1lel gains were made in both fluency and language. There was an increase in both fluency and positive (desirable) language responses. At follow-up, an opposing parallel was noted. Findings revealed a slight increase in stuttering frequency with a concurrent increase in negative (undesirable) language responses.

Although overall improvement was made in both speaking behavior and language usage from the initial baseline to follow-up baseline, the shift made from the end of conditioning to follow-up was notable suggesting a possible relationship of language responses to stuttering: as the negative (undesirable) language responses increased and the positive (desirable) language responses decreased, stuttering frequency increased. Prichard (1971) concluded that it was essential 


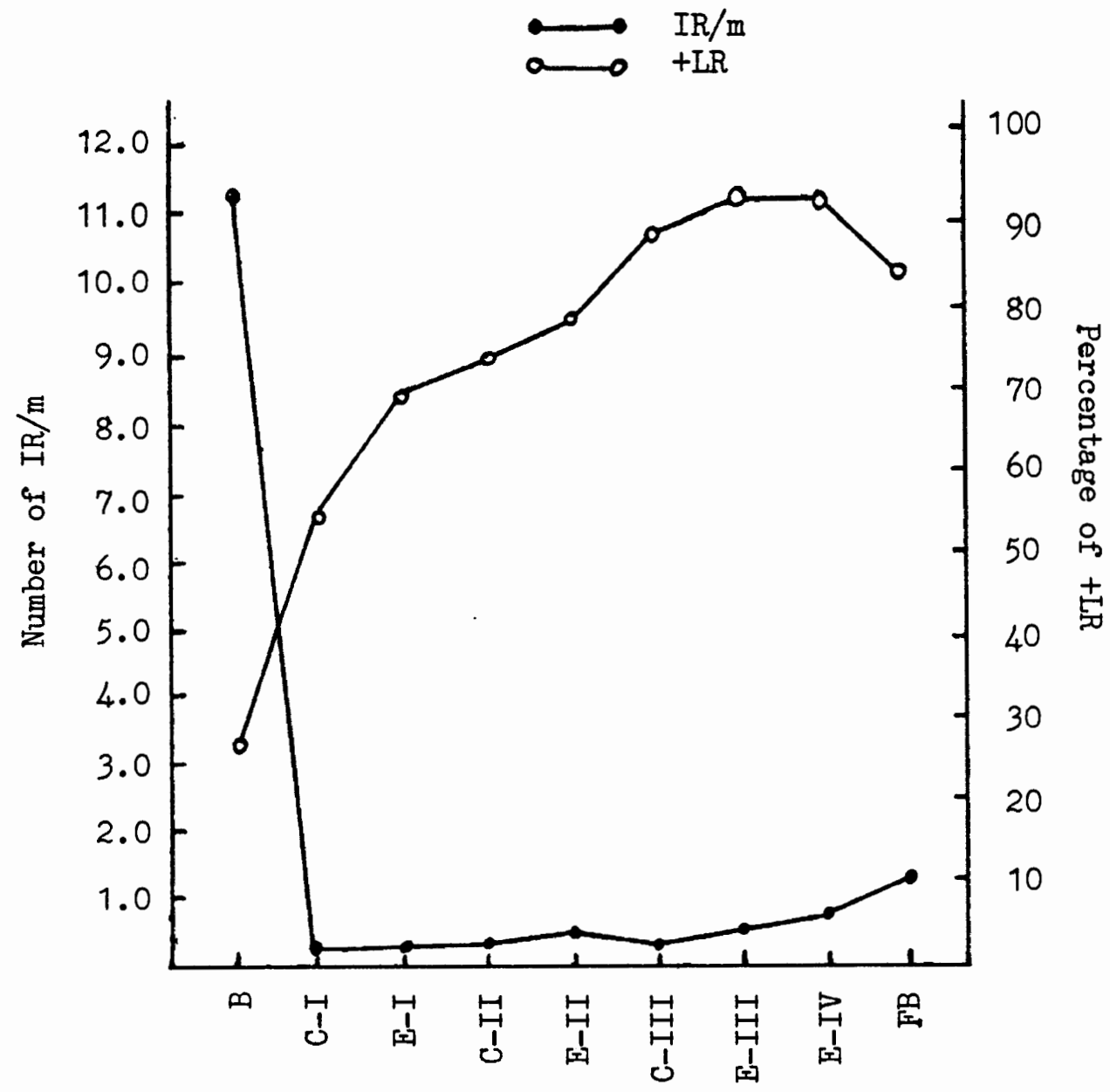

Figure 1. The mean number of interference responses per minute and the percentage of positive language responses in monologue and dialogue settings for baseline sessions and the videotaped sessions of conditioning, extinction and follow-up baseline.

for the person who stutters to develop a repertoire of positive (desirable) language responses,". . thereby enabling him to semantically reorganize his 'feelings' or attitudes about himself as a speaker."

Culatta and Rubin (1973) developed an initial fluency management program which they administered to six subjects. The program, cognitive in nature, was based on the philosophy of responsibility 
for and control of one's speech behavior. The program included eleven stages, culminating in a demonstration of fluency. The first six stages were philosophically based, orienting the stuttering client to use a specific vocabulary when talking about his speech; he had to verbally assume responsibility. The last five stages were performance oriented, manipulating the actual stuttering behavior.

Pre- and postorientation baselines measuring the percentage of stuttered words were obtained. Also, a pre- and postorientation questionnaire consisting of open-ended questions requiring complete responses was administered to assess expressed attitude change during the program. Results regarding stuttering frequency were analyzed, indicating a significant reduction in stuttering for all six subjects. With regard to attitude change, language responses revealed by three of the six subjects on the postorientation questionnaires showed a change in attitude on five of the six questions. Their attitudes, consistently negative and pessimistic on the preorientation questionnaire, changed to a more positive, optimistic theme by the postorientation evaluation.

In order to further test the program and the relationship of attitude change to increased fluency, Culatta and Rubin (1973) selected two new subjects. Only the final five stages dealing with performance were administered. The authors postulated that the isolated manipulation of the stuttering behavior would reduce the behavior some but not significantly in the absence of the first six stages aimed at modification of attitude through manipulation of language themes. 
Results were consistent with the authors' predictions. Only a slight reduction in stuttering behavior between pre- and postevaluation was evidenced. Postorientation questionnaire responses also revealed little or no change from the initial pessimism about stuttering behavior. At this point, the subjects reported much frustration and confusion as they attempted to speak fluently outside the clinic setting. To ease some of the discomfort experienced by the subjects and in part to see if the theoretical portion of the program could be effective after the performance portion, the entire program was administered to the two subjects. By the end, one subject showed a marked increase in fluency while the other showed a marked change in attitude and an apparent understanding of his increased fluency since the initial baseline questionnaire.

The authors emphasized that the program, although it was not a substitute for a complete intervention experience, stimulates positive change in attitudes expressed and in speech behavior. Even though none of the subjects were fluent at the end of the program, many reported they were better able to deal with their thoughts, behaviors and feelings.

\section{Conclusions}

Until this time, clinical research dealing with the relationship between stuttering and language themes has been meager. Some short-term studies conducted by Shames, Egolf and Rhodes (1969), Egolf, Shames and Blind (1971), Prichard (1971) and Culatta and Rubin (1973) indicate that thematic modification of the stuttering client's 
language from undesirable to more desirable seems to promote an increase in fluency. Since there seems to be a relationship between increased desirable language usage and increased fluency of clients during an intervention program, there also may be some relationship between desirably modified language and the long-term maintenance of fluency improvement. 


\section{CHAPTER III}

\section{METHODS}

Subjects

Twenty-two former Portland State University adult stuttering clients were asked to participate in the study. Criterion for their selection was based on prior participation in Ginter's 1979 study on fluency maintenance. Findings indicated that thirteen of the twentytwo subjects had maintained fluency improvement within the "normal" range and nine had not. Of the thirteen maintainers asked to participate, eleven responded. Questionnaires sent to the other two maintainers were returned, undeliverable as addressed; current addresses were not available. Of the nine non-maintainers asked to participate, five responded. Two of the four non-respondent questionnaires were returned, undeliverable as addressed; another non-maintainer refused to participate at the time of the follow-up phone call; the last of the four indicated a desire to participate but failed to respond after four follow-up phone calls.

All subjects had been enrolled in Casteel's Four Stage Stuttering Program between Winter Term 1973 and Spring Term 1977 and had terminated the program in Stage III, Stage IV or Self-Maintenance. Their durations of clinical intervention ranged from one to five terms. The elapsed time since termination of speech services for the subjects ranged from two to seven years. Since the time of data 
collection for Ginter's study (1979), one of the sixteen respondents of this study had participated in another program, The Precision Fluency Shaping Program.

\section{Instrumentation}

The instrument used for collection of language responses was a buff-colored, three page questionnaire (Appendix A) modified on the basis of pilot study data. The questionnaire was designed to sample the language former stuttering clients use to describe their attitudes and beliefs about stuttering and fluency. It included one general information question and twelve open-ended questions regarding the stuttering client's attitudes and beliefs about his speech. Two to three lines were provided for each question response, with additional space made available if necessary. Some of the questions were developed by this examiner in collaboration with Jack Hegrenes, Associate Professor of Social Work at Crippled Children's Division, University of Oregon Health Science Center, with Robert Casteel, Professor of Speech Pathology at Portland State University, and with Robert Stone, Assistant Professor of Speech Pathology at Indiana Medical School. Other questions were drawn from sources such as Williams (1957), Kent (1961) and Culatta and Rubin (1973), with some minor revisions. Reliability and validity of this instrument were not determined.

For tracking the response units of questionnaire responses, the "Thematic Analysis Form" (Appendix B), an instrument constructed by Stone and Casteel (1975) for categorizing clinician and client language responses, served as a model. Although the form was developed 
for use with functional voice cases and their clinical management, it is not disorder specific. It addresses the same major thematic parameters addressed in Casteel's Stuttering Program and was therefore used as the basis for categorizing the thematics of responses made by the subjects of this study. Some minor form modifications were made by this examiner for response tabulating purposes and for thematic parameter categorization.

The modified form (Appendix $C$ ), from left to right, included space for the written response unit. Next, five columns were designated for respondent number, question number and response unit number identification. By way of explanation, they included:

1. Respondent number: In this column, the number code from the subject's questionnaire was recorded.

2. Question number: In this column, the number corresponding to the question on the questionnaire was recorded.

3. Response: In this column, a "No" was recorded if the subject did not respond to the question; a "Yes" was recorded if he did respond.

4. Sentence number, Response unit number: In order to identify the response unit to be analyzed, for example, if the response unit is only a phrase, as well as identifying the sentence from which it originated (since more than a one sentence response could be given to each question) ordered pairs of numbers were used. The first number in the pair indicated the sentence number and the second number in the pair indicated the response unit number to be analyzed within that sentence. So, for example, if the response to the second question included two sentences with each sentence containing three response units for analysis, the series of sentence number, response unit number ordered pairs would look like this: 1,$1 ; 1,2$; 1,$3 ; 2,1 ; 2,2$; and 2,3 .

5. Behavior change: In this column, a "No" was recorded if a response unit was unrelated to behavior change and therefore irrelevant or ambiguous to the study and 
not analyzable. A "Yes" was recorded if a response unit was related to behavior change, whether desir$a b l y$ or undesirably, and therefore analyzable.

The remaining portion of the form provided space to categorize response units on the four overall thematic parameters. The four parameters were subdivided into seven parameter pairs, each one addressing the bipolar components of each parameter: undesirable versus desirable. The parameters included.

1. Description of behavior

a. Obscure vs. Physiologically descriptive

b. Passive vs. Active

c. Negative vs. Positive

2. Responsibility for behavior

a. Outside vs. Within

3. Attitude about speech performance

a. Pessimistic vs. Optimistic

4. Awareness of behavior

a. Ignorant of incorrect vs. Knows incorrect

b. Ignorant of correct vs. Knows correct

Besides the questionnaire and "Thematic Analysis Form" used in this study, baseline and follow-up Stuttering Severity Instrument (Riley, 1972) scores previously obtained provided the level of maintained fluency improvement for each subject (Ginter, 1979). The Stuttering Severity Instrument (SSI) yields a numerical score of severity based upon the measurement of three observable components of stuttering: frequency of stuttering, duration of stuttering occurrence and physical concomitants that may be used with the dysfluent speech (Appendix D). The severity scores for subjects were based on the revised severity ratings for the SSI (Appendix E) developed by 
Kimbal1 (1975).

$\underline{\text { Data Collection }}$

For this study, the questionnaire, accompanied by a Letter of Intent (Appendix F) and an Informed Consent Form (Appendix G) deve1oped in compliance with Portland State University's Human Subjects Research Committee Guidelines, were mailed to each of the twenty-two subjects initially chosen from Ginter's (1979) study. A selfaddressed, stamped envelope for questionnaire and consent form return was also enclosed. Questionnaires were numerically coded to insure subject anonymity and to enable the examiner to identify nonrespondents so they could be contacted about participation in the study. If subjects failed to respond to the questionnaire within two weeks of the initial mailing, postcards (Appendix H) were sent as reminders. Follow-up phone calls were also used when necessary. Upon receipt of the completed questionnaires, "Thank You" postcards (Appendix I) were sent to subjects.

Besides gathering language responses, the Stuttering Severity Instrument (SSI) scores previously obtained in the Ginter (1979) follow-up study also were utilized for the current study.

At the conclusion of data collection and analysis, data were destroyed to insure subject anonymity.

Language Response Recording and Categorizing Procedures

For each subject, questionnaire responses were divided into units for analysis. To be an analyzable unit, it had to express a complete thought. These units were recorded in the space provided on 
the "Modified Thematic Analysis Form" (Appendix C). Respondent number, question number, and response unit identifiers were recorded in the first five columns provided on the form.

The last seven columns on the form served to describe the thematic parameters to be scored. The analyzable response units for each subject were categorized according to the seven thematic parameters. For each response unit, each of the seven bipolar parameter pairs were scored with regard to undesirable and desirable components. A minus ( $(-)$ indicated undesirable and a plus (+) indicated desirable; for a parameter pair which was not applicable for a given response unit, a zero (0) was recorded. A sample analysis is included (Appen$\operatorname{dix} J$ ).

For each subject, the total number of undesirable language responses (ULR or - ) and desirable language responses (DLR or + ) tracked were separated from each other. The sums of each response class, undesirable and desirable, were calculated. Percentage scores for each of the two response classes were determined, representing the frequency of each type of language response class for a given sub ject.

\section{$\underline{\text { Reliability }}$}

Two second year graduate students who had experience in developing language themes, assisted this examiner in order to determine inter-judge reliability for the categorization of questionnaire responses on the Modified Thematic Analysis Form. Initially, each graduate student was provided a set of guidelines. Approximately eight hours of training followed during which additional guidelines 
(Appendices $\mathrm{K}$ and $\mathrm{I}$ ) were formulated and sample responses were categorized. For training purposes; the pilot data were used; other training materials were drawn from Williams (1957), Sander (1970) and Rhodes, Shames and Egolf (1971). When training was completed, 10 percent of the study questionnaire responses were randomly selected from the 192 questionnaire responses. They were then analyzed by the three judges to determine inter-judge reliability. Based on 50 percent of these randomly selected responses, examiner intra-judge reliability was determined.

Inter- and intra-judge reliability was determined for three levels of analysis: (1) the division of questionnaire responses into response units; (2) the overall categorization of response units as undesirable or desirable; and (3) the seven thematic parameter judgements. Pearson product-moment correlation was used to calculate inter- and intra-judge reliability agreements.

Inter-judge reliability was based on an analysis of twenty randomly selected questionnaire responses. The examiner's division and scoring of responses and the means of results obtained by the two judges dividing and scoring the same responses were correlated. The correlation of the two sets of scores was .97 for the division of responses into response units and .93 for the overall categorization of response units as undesirable or desirable. For the seven thematic parameter judgements, correlations were as follows: (1) obscure/physiologica1, .88; (2) passive/active, .93; (3) negative/ positive, .83; (4) outside/within, .93; (5) pessimistic/optimistic, .85 ; (6) ignorant of incorrect/knows incorrect, .80; and (7) ignorant 
of correct/knows correct, .86 .

The examiner analyzed all 192 questionnaire responses. Corresponding response results obtained in this analysis were compared with the results from 50 percent of the initial responses tracked for inter-judge reliability. The correlation of the two sets of scores was 1.00 for the division of questionnaire responses into response units and .99 for the overall categorization of response units as undesirable or desirable. For the seven thematic parameter judgements, correlations were as follows: (1) obscure/physiological, .95; (2) passive/active, 1.00; (3) negative/positive, 1.00; (4) outside/ within, 1.00 ; (5) pessimistic/optimistic, 1.00; (6) ignorant of incorrect/knows incorrect, .80 ; and (7) ignorant of correct/knows correct, 1.00 .

\section{Data Analysis}

The procedure used for statistical treatment of the data was chosen in order to compare the data from Ginter's (1979) maintenance study and the language response types used by some of the same subjects in this study. The Spearman Rank-Order Correlation Coefficient (RHO) was used to determine the relationship between the degree of maintained fluency improvement and the overall language response types used. Numerical ranks from low to high were used to represent poor to better maintained fluency improvement levels and language response type percentages. Significance was set at the .05 level. 


\section{RESULTS AND DISCUSSION}

\section{Results}

The question investigated in this research was: What is the relationship between the degree of maintained fluency improvement and the type of language an individual uses to describe his speech? A questionnaire was developed to elicit complete language responses from the subjects of this study. The Modified Thematic Analysis Form designed by this author was used to record the language response types according to the seven thematic parameters discussed earlier. The data were statistically analyzed using the Spearman Rank-Order Correlation Coefficient (RHO).

In examining all of the data, it became evident that the question asked in this study was somewhat ambiguous in that it could be looked at in at least two ways. The ". . degree of maintained fluency improvement . . ." addressed by the study question could indicate maintained fluency improvement as it is represented by a single follow-up SSI score or as it is represented by a more comprehensive score of overall clinical gain maintained at the time of the Ginter (1979) follow-up. Since the latter is the more comprehensive of the two, its significance shall be reported first.

Those subjects who had made and maintained greater overal1 clinical gains in fluency from the time of baseline to the time of 
follow-up also seemed to use the most desirable language responses; those for whom the gain was slight or non-existent, used language which tended to be less desirable. To test this, the Spearman RankOrder Correlation Coefficient was used. The overall fluency gain that subjects made from the entrance level SSI (Baseline) to followup SSI as reported by Ginter (1979) and the corresponding percentages of desirable language responses from this study were ranked and compared (Table I). The resultant Spearman RHO was .64, a moderate correlation indicating a substantial relationship (in a range of 40 70). It was significant beyond .02 . Those who had made the greatest overall clinical gain in fluency and maintained most or all of the gain over time, even if they were not judged to be "normally" fluent by the SSI scale (Normal $0-8$ ), also used a greater percentage of desirable language responses on the questionnaire.

The Spearman Rank-Order Correlation Coefficient also was utilized to determine the correlation between the degree of maintained fluency as represented by the subjects follow-up SSI scores from Ginter's (1979) study and the subjects corresponding percentages of desirable language responses obtained from this study. The SSI scores and percentages of desirable language responses were ranked and compared (Table II). The resultant Spearman (RHO) was .44 , a moderate correlation also (in a range of $40-70$ ). However, it was not significant at the .05 level.

Although language response types did not separate the maintainers and non-maintainers into two distinctive groups, increases in percentages of desirable language responses were moderately related 
TABLE I

SPEARMAN RHO RANKINGS FOR CLINICAL GAINS AND

PERCENTAGES OF OVERALL DESIRABLE

LANGUAGE RESPONSE USAGE

\begin{tabular}{|c|c|c|c|c|}
\hline Subject & $\begin{array}{l}\text { Points of } \\
\text { Clinical } \\
\text { Gain }\end{array}$ & $\begin{array}{c}\text { Overall } \\
\text { DLR } \\
\%\end{array}$ & $\begin{array}{c}\text { Clinical } \\
\text { Gain } \\
\text { Rank }\end{array}$ & $\begin{array}{c}\text { Overal1 } \\
\text { DLR } \\
\text { Rank }\end{array}$ \\
\hline 1 & 9 & 55.0 & 7 & 4 \\
\hline 2 & 14 & 70.0 & 13 & 12 \\
\hline 3 & 10 & 65.0 & 8 & 9 \\
\hline 4 & 7 & 47.0 & 5 & 2 \\
\hline 5 & 12 & 60.0 & 10 & 6.5 \\
\hline 7 & 6 & 69.0 & 4 & 11 \\
\hline 8 & 11 & 77.0 & 9 & 15 \\
\hline 10 & 0 & 64.0 & 2.5 & 8 \\
\hline 11 & 18 & 72.0 & 15 & 13.5 \\
\hline 12 & 0 & 48.0 & 2.5 & 3 \\
\hline 13 & -6 & 58.0 & 1 & 5 \\
\hline 15 & 8 & 46.0 & 6 & 1 \\
\hline 16 & 13 & 66.0 & 11.5 & 10 \\
\hline 18 & 17 & 60.0 & 14 & 6.5 \\
\hline 19 & 13 & 72.0 & 11.5 & 13.5 \\
\hline 20 & 23 & 78.0 & 16 & 16 \\
\hline
\end{tabular}


TABLE II

SPEARMAN RHO RANKINGS FOR FOLLOW-UP SSI SCORES AND PERCENTAGES OF OVERALI DESIRABLE

LANGUAGE RESPONSE USAGE

\begin{tabular}{|c|c|c|c|c|}
\hline Subject & $\begin{array}{c}\text { Follow-up } \\
\text { SSI } \\
\text { Score }\end{array}$ & $\begin{array}{c}\text { Overall } \\
\text { DLR } \\
\%\end{array}$ & $\begin{array}{l}\text { Follow-up } \\
\text { SSI } \\
\text { Rank }\end{array}$ & $\begin{array}{c}\text { Overa11 } \\
\text { DLR } \\
\text { Rank }\end{array}$ \\
\hline 1 & 0 & 55.0 & 15.5 & 4 \\
\hline 2 & 8 & 70.0 & 6 & 12 \\
\hline 3 & 1 & 65.0 & 13.5 & 9 \\
\hline 4 & 0 & 47.0 & 15.5 & 2 \\
\hline 5 & 7 & 60.0 & 7 & 6.5 \\
\hline 7 & 13 & 69.0 & 3 & 11 \\
\hline 8 & 3 & 77.0 & 10.5 & 15 \\
\hline 10 & 6 & 64.0 & 8 & 8 \\
\hline 11 & 11 & 72.0 & 4 & 13.5 \\
\hline 12 & 16 & 48.0 & 2 & 3 \\
\hline 13 & 37 & 58.0 & 1 & 5 \\
\hline 15 & 5 & 46.0 & 9 & 1 \\
\hline 16 & 1 & 66.0 & 13.5 & 10 \\
\hline 18 & 10 & 60.0 & 5 & 6.5 \\
\hline 19 & 3 & 72.0 & 10.5 & 13.5 \\
\hline 20 & 3 & 78.0 & 10.5 & 16 \\
\hline
\end{tabular}


to the maintenance of overall fluency gains and increasingly better follow-up SSI scores.

\section{Discussion}

By employing the Spearman Rank-Order Correlation Coefficient to compare the data, two moderate correlations were found: a relationship between language themes and the degree of maintained fluency as represented by the follow-up SSI scores (Ginter, 1979) and also a relationship between language themes and the degree of overall fluency gain from baseline to follow-up (Ginter, 1979). From the data analyzed, it appears that those subjects who exhibited a better SSI score at the time of follow-up also used a greater percentage of desirable language. It also appears that those subjects who had improved the most or made the most gain in fluency from baseline to follow-up and maintained the overall gain, used a greater percentage of desirable language. On the basis of these two correlations, there appears to be a moderate relationship between the usage of overa11 desirable language and a better follow-up SSI score and/or greater overall fluency gain from baseline to follow-up. These data add some new information to the findings of numerous researchers (Shames, Egolf and Rhodes, 1969; Egolf, Shames and Blind, 1971; Prichard, 1971 ; and Culatta and Rubin, 1973) who suggest that the use of overall desirable language themes seems to play a major role in the establishment of fluency. Although this study seems to support a relationship between desirable language themes and maintained fluency improvement, the degree of relationship is difficult to state conclu- 
sively at this point due to several uncontrolled variables which will be discussed later.

Overall, only three out of the sixteen subjects who participated used a greater amount of undesirable language than desirable. Possible reasons for this vary for the subjects involved. One of the subjects, Subject 12 , entered the program with a baseline severity of 16. About 4 years later, at follow-up, his severity was judged as 16. His higher percentage of undesirable language responses may be related to, or may even account for, his lack of any maintained fluency gain. Another, Subject 4, was rated a 7 at baseline and a 0 at follow-up; the person made a 7 point gain, but, since he/she was judged as "normal" to begin with, language may not have been as influential to attain or maintain fluency improvement. The last of the three subjects who used more undesirable language than desirable language, Subject 15, made a gain of 8 from a baseline severity of 13 (Mild) to a follow-up severity of 5 (Normal). One possible reason for a greater percentage of undesirable language than desirable language could be due to the length of intervention; Subject 15 was seen for only one term. One term is a short time to synthesize and learn to use the language of responsibility (desirable language).

When separating the group of sixteen subjects into maintainers (those who maintained fluency improvement within the established normal limits of $0-8$ on the SSI scale) and non-maintainers, no conclusions could be drawn. Whether a person maintained or did not maintain fluency between 0 and 8 (Normal) on the SSI scale did not seem to be the issue. Rather, the degree of maintained fluency improve- 
ment (as represented by the SSI) and especially, the degree of maintained fluency gain were the major issues. The increasingly greater gain (RHO of .64) and the increasingly better SSI scores (RHO of .44) were moderately related to overall desirable language usage (Appendix M).

As stated before, from this study data it is known that those subjects who maintained a greater degree of fluency improvement and/ or those who made the greater gain in fluency and maintained the gain also seemed to use a higher percentage of desirable language. What is unknown, however, is whether the language used made a similar gain or drop in desirability as the fluency did. Unlike this study, Prichard's (1971) study had access to all necessary baseline data. The study demonstrated, although on a small scale, a more parallel relationship between language themes and fluency establishment/maintained fluency. After baseline was established for both stuttering behavior and thematics, intervention was begun on both. During intervention, as her subject became more fluent, he also used more desirable language themes to describe himself and his speech. At the time of post-testing, he had increased his fluency as well as his desirable language. Four weeks after the last post-testing session (Stage IV), he was followed up. Although he showed a slight decrease in fluency and desirable language themes used, the decrease was not significant. What seemed more significant was that, again, there was a parallel or corresponding shift in language themes and fluency suggesting that they may be, in some way, dependent on each other and in turn, may be related to overall maintenance. Baseline data on lan- 
guage, then, was a critical missing component in this study that, if available, may have allowed for more conclusive data regarding the degree of relationship between language usage and fluency establishment and maintenance. For instance, if there had been baseline data for thematics, conclusions regarding the effectiveness of the thematic modification portion of Casteel's Stuttering Program could have been drawn. Even more far reaching, the role and effectiveness of thematic modification in modifying stuttering behavior and in maintaining fluency could have been drawn, i.e., Did the subjects modify their language from the time of initial intervention (baseline) to post-test and from the time of post-test to follow-up (study questionnaire) and did the language modification, if there was any, have any effect on the stuttering behavior? Hypothetically, if there had been an increase in desirable language usage and a decrease in undesirable language usage from baseline to post-test and/or from posttest to follow-up for those who maintained a greater degree of fluency, one could more accurately conclude that the language used probably did play a role in the establishment and in the maintenance of fluency gain. If there was no significant increase in desirable language and decrease in undesirable language or if the type of language used remained the same from baseline to post-test to follow-up in those who maintained fluency improvement, one would probably conclude that language may not be that important to fluency establishment and/or maintenance. However, the language the person used coming into a program might be a predictor of future maintenance. Without any baseline data on language, it is difficult to 
determine the role of language. First of all, do certain types of language themes play a role in stuttering and/or fluent behavior? If so, is the modification of language more significant for fluency establishment or for fluency maintenance? This study can only conclude that there seems to be a moderate relationship between a greater percentage of overall desirable language responses and greater maintained fluency improvement as represented by maintained clinical gain and follow-up SSI level.

A critical component of any study has to do with the timing of of the study. Ideally, this study should have been conducted concurrently with the maintenance study (Ginter, 1979). Since there was a year between data collections for the studies, other variables could be operating to influence the data obtained (i.e., those who made and maintained greater gains also used a higher percentage of desirable language themes). Such a variable involved Subject 13. This person was actually judged as more severe at the time of follow-up than at baseline (Ginter, 1979); this person "lost ground" instead of making and maintaining any gain. Yet, the language themes used to respond to questionnaire items for this study were more desirable overal1 than undesirable. A possible variable to account for this deviation goes back to the problem of poor study timing. In that year between studies, Subject 13 had participated in another stuttering intervention program, the Precision Fluency Shaping Program. The responses made to questions on this study's questionnaire reflected overall desirable content and indicated increased satisfaction for the current level of fluency. One might speculate that if subject $13^{\prime} \mathrm{s}$ 
severity level had been judged at the time this study questionnaire was distributed, Subject 13's follow-up SSI score may have been better due, in some way, to participation in another program. An SSI score that had shown any gain at all may have been reflected in a higher correlation for this study. The timing factor also may affect other subjects; however, none were as obvious as for Subject 13 . 


\section{CHAPTER V}

\section{SUMMARY AND IMPLICATIONS}

\section{Summary}

This research examined the relationship between the degree of maintained fluency improvement and the type of language used to respond to questions directly and indirectly related to speaking behavior. The subjects included sixteen former Portland State University stuttering clients who had participated in the Ginter (1979) study on fluency maintenance. The subjects responded to a thirteen item questionnaire dealing with themselves and their speaking behavior. Responses were recorded on the Modified Thematic Analysis Form developed by this examiner and analyzed according to guidelines set down by Stone and Casteel (1975) and this examiner.

Results of this research indicate that the degree of maintained fluency improvement, as represented by overall clinical gains and by follow-up SSI scores (Ginter, 1979), correlates moderately with desirable language usage. This suggests, then, that greater gain and better SSI scores seem to be related to greater usage of overall desirable language.

The present research adds to that of others (Johnson, 1955; Williams, 1957; Shames, Egolf and Rhodes, 1969; Egolf, Shames and Blind, 1971; Prichard, 1971; Culatta and Rubin, 1973; and Casteel, 1976) who have found that there seems to be a relationship between 
fluency and language or thematics. While other research has indicated a relationship between the establishment of fluency and the use of desirable language during an intervention program, this research suggests that desirable language also may be related to overall clinical gain and fluency improvement that is maintained over an extended period of time. Results seem to indicate that those subjects who had farther to go to become fluent, thereby making greater gains overall and maintaining the greater gains over time, also talked more desirably about their speech. Reasons for the gains and maintenance of the gains may, in part, be related to the more desirable, realitybased language used by those subjects.

\section{Research Implications}

Numerous implications for further study are generated by this research. One would be to replicate this study using an interview format for language response collection. Unlike the questionnaire used in this study, an interview format would allow for clarification of any study questions. A possible adjunct to the interview format would be to have another trained person behind a one-way mirror doing an SSI on the subject as the experimenter is interviewing. In this way, the stuttering frequency level (as determined by the SSI) and the language response data would be concurrent. Whether interview format or questionnaire format, effort should be made to develop a more formal, standardized instrument for data collection.

Since this type of analysis is relatively new and specific procedures for it inadequately documented, the scoring procedures should 
continue to be refined. For example, further clarification and specification of the guidelines pertaining to the parameters obscure/ physiological, ignorant of incorrect/knows incorrect and ignorant of correct/knows correct need to be addressed in order to make their analyses more independent of each other. Also, in scoring two of the parameters, negative/positive and passive/active, this examiner found that judgement could be made in an either-or fashion but scaling the scores of these two parameters may be a more precise method of judgement. A study also could be done focusing on only certain parameters, not necessarily a11 seven. For example, an alternative to judgement of all seven parameters is judgement of only the first three parameters; they include Descriptive/Obscure, Active/Passive and Positive/Negative. The scoring of these three parameters could then be compared and contrasted in a scaled versus either-or manner. One might experiment with different breakdowns of responses for analysis, comparing and contrasting variations. For example, responses could be judged word-by-word; guidelines would need to be developed. Or, responses could be broken down by response phrases, as in this study, judging parameter by parameter. A third way to judge might be to look at the entire response to a particular question and judge it as overall desirable or undesirable; this judgement would be more subjective and difficult to document.

Another possible offshoot of this study may be to compare and contrast the language responses of similar population samples from Casteel's program and from another program that does not include thematic modification as part of its program. 
Another interesting project would be to do a covert study on beginning clinicians in stuttering clinic, recording samples of the language they use with their clients. Recordings could be done at the beginning of the term (Baseline), at mid-term time and at the end of the term. The data obtained could have clinical implications regarding program training.

\section{Clinical Implications}

In conducting this study, clinical implications were soon apparent. The goals of Casteel's program are to modify stuttering behavior as well as to modify client thematics. Since Casteel's program addresses client thematics, or language, during intervention, there is a need to secure a more formal baseline measure of client thematics. Previously, a measure of client language usage was based on very informal, clinical impression. In management, goals are developed and steps toward those goals should be charted. Stuttering behavior is charted from a formal baseline through conditioning to post-testing. Since thematic modification is also one of Casteel's goals, it should be subject to the same accurate charting as any change in fluency (or stuttering behavior) is. Currently, however, this change is not being charted. A pre-post test questionnaire (Appendix N: Sample) could provide a means for determining the quality of a client's language behavior or thematics. An analysis similar to the one done for this study could be done on the language of clients as they go through the program. Change could then be charted and related to fluency change and to long-term maintenance. Imple- 
mentation of a means for charting language change also could lead to future research of Casteel's program and of stuttering behavior in general. 


\section{BIBLIOGRAPHY}

AINSWORTH, S., The relationship of theory and clinician characteristics of therapy for stutterers: A discussion of the Murphy and Wingate papers. In R. W. Rieber (Ed.), The Problem of Stuttering: Theory and Therapy. New York: Elsevier (1977).

ANDREWS, G., and CUTLER, J., Stuttering therapy: The relation between changes in symptom level and attitudes. J. Speech Hearing Dis., 39, 312-319 (1974).

BAR, A., The shaping of fluency not the modification of stuttering. J. Comm. Dis., 4, 1-8 (1971).

BLOODSTEIN, 0., Stuttering as tension and fragmentation. In J. Eisenson (Ed.), Stuttering: A Second Symposium. New York: Harper and Row Publishers (1975).

BLOODSTEIN, O., Foreword. In R. W. Rieber (Ed.), The Problem of Stuttering: Theory and Therapy. New York: Elsevier (1977).

BRUTTEN, G. J., Stuttering: Topography, assessment and behavior change strategies. In J. Eisenson (Ed.), Stuttering: A Second Symposium. New York: Harper and Row Publishers (1975).

CASTEEL, R. C., Modification of stuttering through a series of discrimination tasks. Paper presented at the ASHA Western Regiona1 Conference, Portland, Oregon, 28 May 1976.

CASTEEL, R. C., and MCMAHON, J., The modification of stuttering in a public school setting. J. Childhood Comm. Dis., 2, 6-17 (1978).

CULATTA, R. A., and RUBIN, H., A program for the initial stages of fluency therapy. J. Speech Hearing Res., 16, 556-568 (1973).

CUTLER, J., Assessing changes in communication attitudes following the behavior modification of stuttering. Bachelor's thesis, University of New South Wales (1973).

EGOLF, D. B., SHAMES, G. B., and BLIND, J. J., The combined use of operant procedures and theoretical concepts in the treatment of an adult female stutterer. J. Speech Hearing Dis., 36, 414-421 (1971).

FALCK, F. J., Stuttering: Learned and Unlearned. Springfield: Charles C. Thomas Publisher (1969). 
FRASER, M., Stuttering and Its Treatment: The Opinions of Certain Authorities. Speech Foundation of America (1974).

FRASIER, J., An exploration of stutterer's theories of their own stuttering. In W. Johnson and R. Leutenegger (Eds.), Stuttering in Children and Adults. Minneapolis: University of Minnesota (1955).

FREUND, H., Psychopathology and the Problem of Stuttering. Springfield: Charles C. Thomas (1966).

GINTER, P., An investigation of client fluency maintenance between 1972-1977 at Portland State University. Unpublished Master's thesis, Portland State University (1979).

GUITAR, B., Pretreatment factors associated with the outcome of stuttering therapy. J. Speech Hearing Res., 19, 590-600 (1976).

INGHAM, R. J., ANDREWS, G., and WINKLER, R. A., A comparison of the effectiveness of four treatment techniques. J. Comm. Dis., 5, 91-117 (1972).

JOHNSON, W., A study of the onset and early development of stuttering. J. Speech Dis., 7, 251-257 (1942).

JOHNSON, W., People in Quandaries. New York: Harper (1946).

JOHNSON, W., The descriptional principle and the principle of static analysis. In $W$. Johns on and R. R. Leutenegger (Eds.), Stuttering in Children and Adults. Minneapolis: University of Minnesota Press (1955).

JOHNSON, W., Perceptual and evaluational factors in stuttering. In L. E. Travis (Ed.), Handbook of Speech Pathology. New York: Appleton-Century-Crofts (1957).

KENT, L., A retraining program for the adult who stutters. J. Speech Hearing Dis., 26, 141-144 (1961).

KIMBALL, C., Recovery from stuttering in a sample of elementary school children. Unpublished Master's thesis, Portland State University (1975).

LUPER, H. L., Transfer and maintenance. Therapy for Stutterers. Speech Foundation of America. No. 10 (1974).

MURPHY, A. T., Feelings and attitudes. Therapy for Stutterers. Speech Foundation of America. No. 10 (1974).

PERKINS, W. H., Replacement of stuttering with normal speech: I Rationale. J. Speech Hearing Dis., 38, 283-294 (1973). 
PRICHARD, S. J., The structuring of procedures utilized in an adult treatment program. Unpublished Master's thesis, Portland State University (1971).

PRINS, D., Improvement and regression in stutterers following shortterm intensive therapy. J. Speech Hearing Dis., 35, 123-134 (1970).

RHODES, R., SHAMES, G., and EGOLF, D., 'Awareness' in verbal conditioning of language themes during therapy with stutterers. J. Comm. Dis., 1, 30-39 (1971).

RIEBER, R. W., Word magic, self-alienation and stuttering. Folia Phoniatrica, 17, 202-216 (1965).

RILEY, G. D., A stuttering severity instrument for children and adults. J. Speech Hearing Dis., 3, 314-321 (1972).

RUBIN, H., and CULATTA, K., A point of view about fluency. ASHA, 13, 380-384 (1971).

SANDER, E. K., Talking plainly about stuttering: Guidelines for the beginning clinician. Central States Speech Journal, 21, 248255 (1970).

SHAMES, G. H., Operant conditioning and stuttering. In J. Eisenson (Ed.), Stuttering: A Second Symposium. New York: Harper and Row, Publishers (1975).

SHAMES, G. H., and EGOLF, D. B., Operant Conditioning and the Management of Stuttering. Englewood Cliffs, N.J.: Prentice Ha11 $(1976)$.

SHAMES, G. H., EGOLF, D. B., and RHODES, R. C., Experimental programs in stuttering therapy. J. Speech Hearing Dis., 34, 30-47 (1969).

STONE, R. E., and CASTEEL, R. L., Intervention in functional voice problems: Part I, Intervention thematics. (1975).

VAN RIPER, C., Experiments in stuttering therapy. In J. Eisenson (Ed.), Stuttering: A Symposium. New York: Harper and Row (1958).

WHALEY, D. L., and MALOTT, R. W., Elementary Principles of Behavior. New York: Appleton-Century-Crofts (1971).

WILLIAMS, E. E., A point of view about 'stuttering.' J. Speech Hearing Dis., 3, 390-397 (1957).

WISCHNER, G., Behavior theory, behavior therapy and speech deviations. Folia Phoniatrica, 24, 105-149 (1972). 


\section{APPENDIX A}

\section{QUESTIONNAIRE}

Please answer all of the following questions as completely as possible. If more space is needed for responding, use the back of the page, numbering the answers accordingly.

1. If you have participated in any stuttering therapy program since Spring 1978, please indicate in the space provided.

$$
\text { Yes _ No }
$$

If yes, describe the program.

2. What two or three instructions do you give yourself when you start to talk?

3. What, if anything, can you do to improve your speech in a given situation?

4. a. What are two of the circumstances when you stutter the least? 
b. Why do you think this is so?

5. a. What are two of the circumstances when you stutter the most?

b. Why do you think this is so?

6. Explain what happens when you stutter.

7. In any situation, why do you stutter?

8. In any situation, why are you fluent?

9. What is most helpful to you when you are talking?

10. a. Describe the most significant gains you have made in your speech in the past.

-...recently 
b. List two reasons for these gains.

11. Describe your fluency.

12. Describe the most significant benefits you have derived from professional intervention.

13. What advice would you give a young adult who stutters (other than to seek professional help)?

Thank you very much for responding to this questionnaire. If there is anything else you would like to include regarding your speech at the present time, feel free to do so. Your contribution to this study is invaluable and very greatly appreciated. If you would like a summary of the results, please indicate: Yes No - We will see that you get it. Thanks again! 


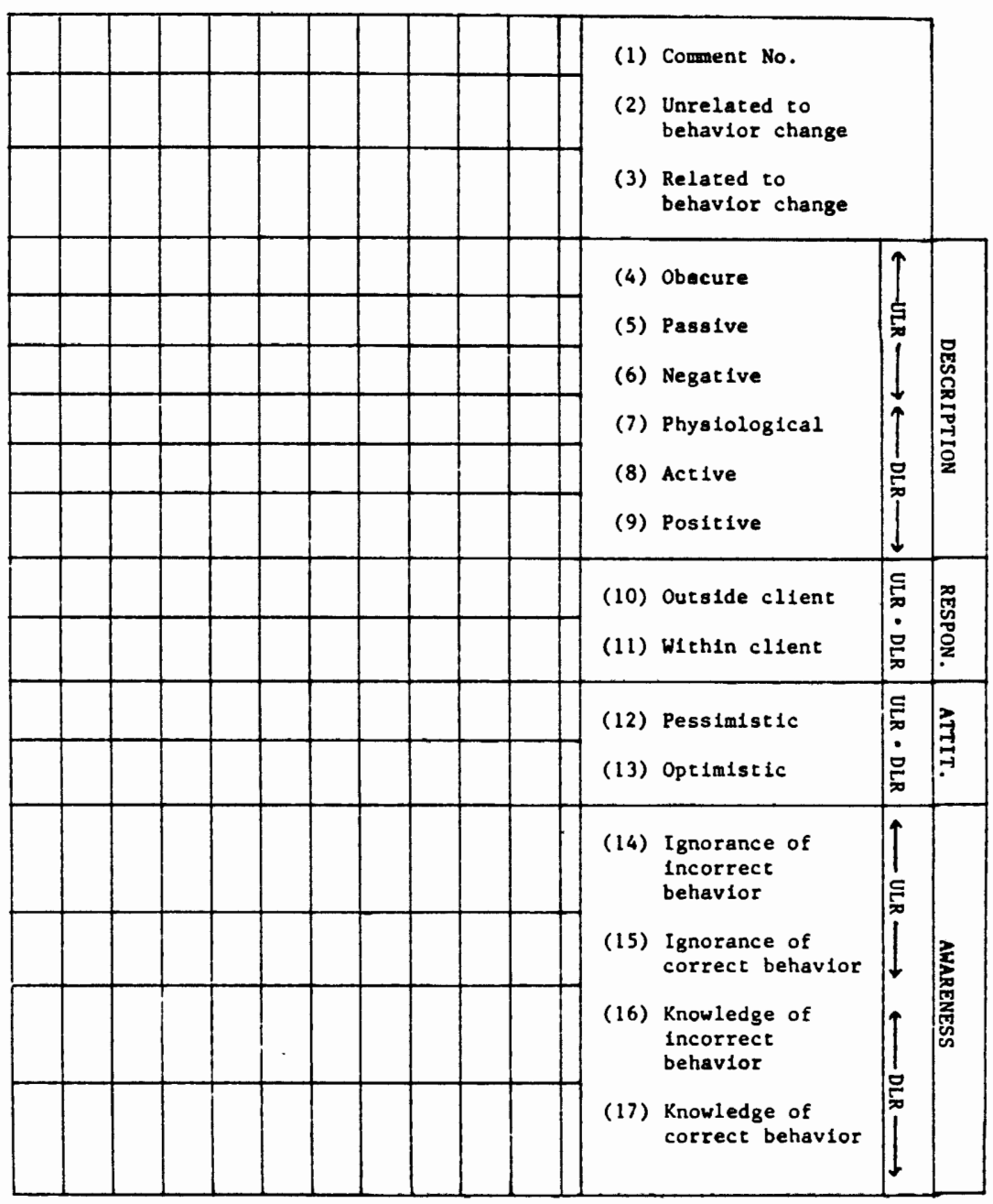




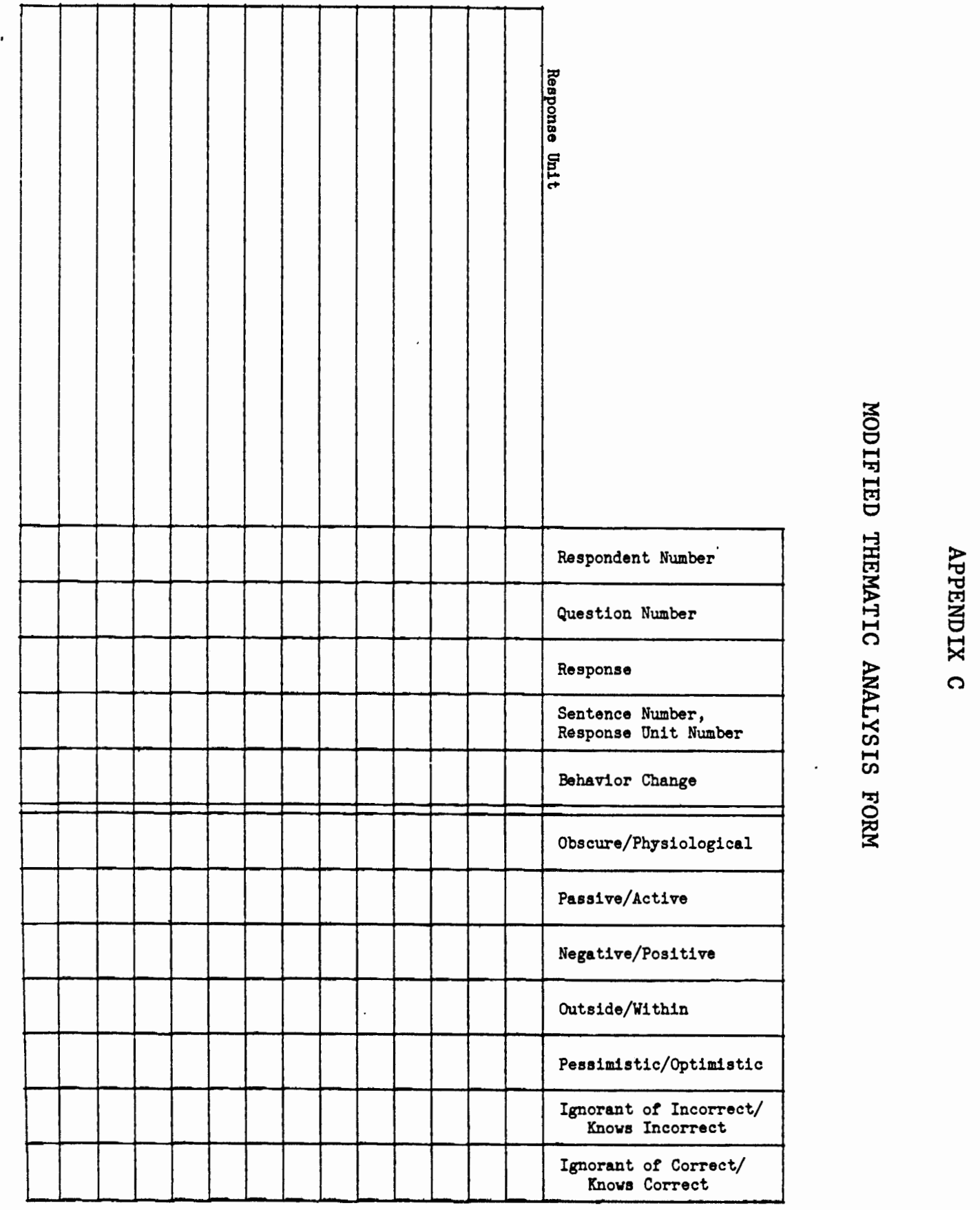




\author{
APPENDIX D \\ STUTTERING SEVERITY INSTRUMENT \\ EVALUATION SCALE \\ (Riley, 1972)
}

Frequency (Use A or B. not both)

\begin{tabular}{|c|c|c|c|c|c|}
\hline \multicolumn{4}{|c|}{ A. For readers. Use $I$ and 2.} & \multirow{2}{*}{\multicolumn{2}{|c|}{$\begin{array}{l}\text { B. For nonreaders } \\
\text { Picture Task }\end{array}$}} \\
\hline \multicolumn{2}{|c|}{ I. Job Task } & \multicolumn{2}{|c|}{ 2. Reading Task } & & \\
\hline $\begin{array}{c}\text { Per. } \\
\text { cenlage }\end{array}$ & $\begin{array}{l}\text { Task } \\
\text { Score }\end{array}$ & $\begin{array}{c}\text { Per. } \\
\text { centage }\end{array}$ & $\begin{array}{l}\text { Task } \\
\text { Score }\end{array}$ & $\begin{array}{c}\text { Per. } \\
\text { centage }\end{array}$ & $\begin{array}{l}\text { Task } \\
\text { Seore }\end{array}$ \\
\hline $\begin{array}{c}1 \\
2-3 \\
4 \\
5-6 \\
7-9 \\
10-14 \\
15-28 \\
29 \text { and up }\end{array}$ & $\begin{array}{l}2 \\
3 \\
4 \\
5 \\
6 \\
7 \\
8 \\
9\end{array}$ & $\begin{array}{c}1 \\
2-3 \\
4-5 \\
6-9 \\
10-16 \\
17-26 \\
27 \text { and up }\end{array}$ & $\begin{array}{l}2 \\
2 \\
5 \\
6 \\
7 \\
8 \\
9\end{array}$ & $\begin{array}{c}1 \\
2-3 \\
4 \\
5-6 \\
7-9 \\
10-14 \\
15-28 \\
29 \text { and up }\end{array}$ & $\begin{array}{r}4 \\
6 \\
8 \\
10 \\
12 \\
14 \\
16 \\
18\end{array}$ \\
\hline
\end{tabular}

Tolal
Frequency
Score
A 1 \& 2
or
B

\title{
Duration
}

\begin{tabular}{lc}
\hline Estımeted Length of Three Longest Blocks & Task Score \\
\hline Fleeting & 1 \\
One half second & 2 \\
One full second & 3 \\
2 to 9 seconds & 4 \\
10 to 30 seconds (by second hand) & 5 \\
30 to 60 seconds & 6 \\
More chan 60 seconds & 7 \\
\hline
\end{tabular}

Total Duration

Score

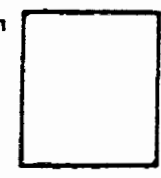

\section{Phyoical Concomitants}

Evaluating Scale: $0=$ none; $1=$ not noticeable unless looking for it: 2 = barely noticeable to casual observer: $\mathbf{3}$ = distracting: $4=$ very distracting; $5=$ severe and painful looking.

1. Distracting Sounds. Noisy breathing. whistling. snifing, blowing, dicking sounds........... 012345

2. Facial grimaces. Jaw jerking, tongue protzuding. lip pressing. jaw muscles tense.............. 012345

3. Head movement. Back, forward, tuming away. poor eye contact. constant looking around....... 012345

4. Extremities movement. Arm and hand move. ment, hands about face, torso movement. leg moverents, toot tapping or swinging......... 0 \& 2 s 5 


\section{APPENDIX E}

REVISED SEVERITY RATINGS FOR SSI

PORTLAND STATE UNIVERSITY

(Kimba11, 1975)

\begin{tabular}{cl} 
Task Score & \multicolumn{1}{c}{$\begin{array}{c}\text { Severity } \\
\text { Description }\end{array}$} \\
$0-8$ & Normal \\
$9-15$ & Mild \\
$16-22$ & Moderate \\
$23-29$ & Moderately Severe \\
$30-36$ & Severe \\
$37-45$ & Very Severe
\end{tabular}


APPENDIX F

LETTER OF INTENT

November 13, 1979

NAME

ADDRESS

CITY, STATE

Dear Name,

I am a graduate student in the Speech and Hearing Science Program at Portland State University, and I am currently developing my Master's Thesis in Speech Pathology.

The short questionnaire enclosed represents part of my thesis project in the area of stuttering. My research involves only a small number of former Portland State University stuttering clients so your responses are very important. The questionnaire data and results will be coded to ensure your anonymity.

I would appreciate it very much if you would read and complete the enclosed Informed Consent form and the study questionnaire and return them to me by November 28, 1979. A self-addressed, stamped envelope is enclosed for your convenience. If you have any questions, you can reach me or leave a message for me, Karen Mathew, at 229-3533.

Thank you very much. I appreciate your assistance.

Sincerely,

Karen Mathew

Speech and Hearing Sciences

Department of Speech Communication

Portland State University

P.0. Box 751

Portland, Or. 97207 


\title{
APPENDIX G
}

INFORMED CONSENT

\begin{abstract}
I, , hereby agree to serve as a subject in the research project on the stuttering Program used at Portland State University conducted by Karen Mathew (Graduate student in the Speech and Hearing Science Department) under the direction of Dr. Robert Casteel.
\end{abstract}

I understand that the study involves providing written responses to questionnaire items. I understand that every response is important since non-responses will jeopardize the study's validity.

I understand that there may be some inconvenience to me associated with this study in that it demands my time (about $\frac{1}{2}$ hour) to read and fill out the questionnaire. I understand that there is no expense on my part; a self-addressed, stamped envelope is provided for questionnaire and "Informed Consent Form" return.

It has been explained to me that the purpose of the study is to learn more about the current Portland State University Stuttering Program.

I may not receive any direct benefit from participating in this study, but my participation may help to increase knowledge which may benefit others in the future.

Karen Mathew (Phone 229-3533) has offered to answer any questions I may have about the study and what is expected of me in the study.

I understand that I am free to withdraw from participation in this study at any time without jeopardizing my relationship with Portland State University. I also understand that if I do choose to participate, my anonymity is ensured.

I have read and understand the foregoing information.

Date

Signature

If you experience problems that are the result of your participation in this study, please contact Richard Streeter, Office of Graduate Studies and Research, 105 Neuberger Hall, Portland State University, 229-3423. 


\section{APPENDIX H}

\section{REMINDER POST CARD}

\section{DATE}

\section{Dear NAME,}

If you have not had the chance to fill out my questionnaire yet, this is a reminder to please send it in as soon as possible. Your participation will help me to get my thesis study "off the ground." If you have any questions, I would be happy to talk with you about them. (Office: 229-3533 or Home: 238-0210)

Thank you very much.

Sincerely,

Karen Mathew 


\section{APPENDIX I}

THANK YOU POST CARD

DATE

Dear NAME,

I want to thank you very much for taking time to respond to my questionnaire. Your thoughtful participation has helped me to get my thesis "off the ground."

Thank you very much.

Sincerely,

Karen Mathew 


\begin{tabular}{|c|c|c|c|c|c|c|c|c|c|c|c|c|c|}
\hline 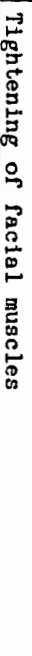 & 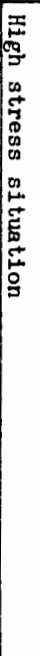 & 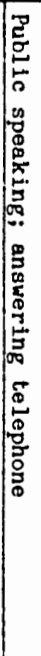 & $\begin{array}{l}3 \\
0 \\
0 \\
0 \\
0 \\
0 \\
0 \\
0 \\
0 \\
2 \\
\vdots \\
0 \\
0 \\
0 \\
0 \\
0 \\
0 \\
0 \\
0 \\
0 \\
0\end{array}$ & 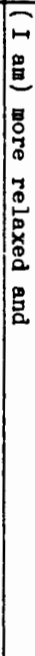 & 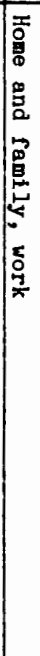 & 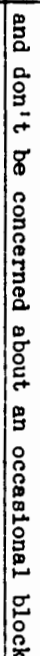 & 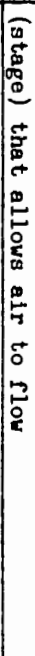 & 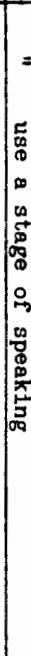 & 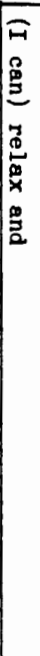 & 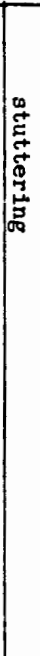 & 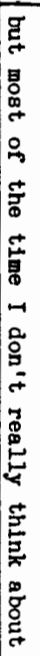 & E & 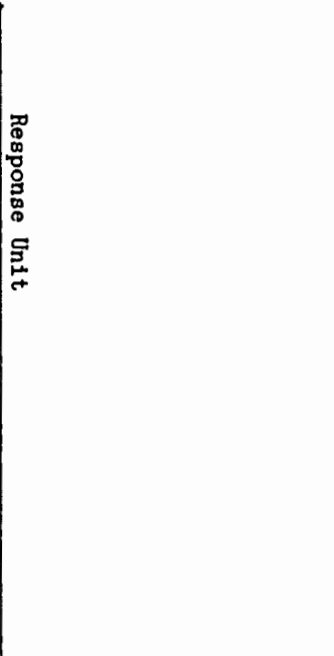 \\
\hline$\sim$ & $N$ & N & N & $N$ & $n$ & N & $N$ & in & N & & N & N & Respondent Number \\
\hline$\sigma$ & $\underset{\sigma}{u}$ & un & $\hat{\sigma}$ & $\hat{\sigma}$ & 周 & $\omega$ & $\omega$ & $\omega$ & $\omega$ & & N & N & Question Number \\
\hline 4 & 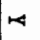 & 4 & $m$ & - 4 & - & 4 & 4 & m & 4 & & 4 & 4 & Response \\
\hline$\vec{z}$ & $\vec{i}$ & $\vec{a}$ & $\vec{\omega}$ & $\ddot{N}$ & $\vec{b}$ & $\vec{a}$ & $\vec{\omega}$ & $\vec{i}_{0}$ & $\vec{\Delta}$ & & $\vec{i}$ & $\vec{b}$ & $\begin{array}{l}\text { Sentence Number, } \\
\text { Response Unit Number }\end{array}$ \\
\hline$\prec$ & is & $z$ & 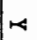 & $\triangleleft$ & $\mathbf{z}$ & 4 & 4 & 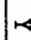 & ma & & 4 & 4 & Behavior Change \\
\hline+ & 0 & & 1 & + & & 1 & + & 0 & + & & 0 & + & Obscure/Physiological \\
\hline 0 & 10 & & 1 & + & & 1 & 1 & + & + & & + & + & Passive/Active \\
\hline 1 & 1 & & 1 & + & & 1 & + & + & + & & 1 & + & Negative/Positive \\
\hline 0 & 0 & & 1 & + & & 1 & 1 & + & + & & + & + & Outside/Within \\
\hline 0 & 0 & & 0 & 0 & & 0 & 0 & + & + & & + & 0 & Pessimistic/Optimistic \\
\hline+ & 0 & & 0 & 0 & & 0 & o & 0 & 0 & & 0 & 0 & $\begin{array}{c}\text { Ignorant of Incorrect/ } \\
\text { Knows Incorrect }\end{array}$ \\
\hline 0 & 0 & & 0 & + & & 0 & + & 0 & + & & 0 & + & $\begin{array}{c}\text { Ignorant of Correct/ } \\
\text { Knows Correct }\end{array}$ \\
\hline
\end{tabular}




\begin{tabular}{|c|c|c|c|c|c|c|c|c|c|c|c|c|c|}
\hline 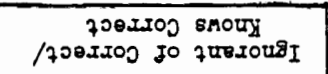 & - & 이 & + & 이 & o & + & + & of & 0 & & + & $\circ$ & 0 \\
\hline 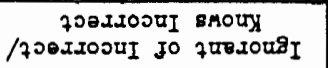 & + & 1 & o & 이 & o & c & o) & 0 & o) & & 0 & $c$ & $\circ$ \\
\hline 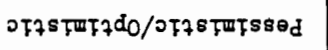 & of & o) & o) & 0 & + & + & $\circ$ & + & 1 & & + & + & + \\
\hline 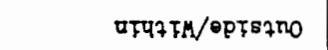 & 0 & of & + & 0 & + & 1 & + & + & 1 & & + & + & 0 \\
\hline 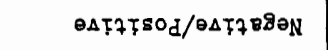 & 1 & 1 & + & 1 & + & 1 & + & 1 & 1 & & 1 & + & + \\
\hline$\triangle \triangle F Z O Y / \triangle \triangle F S E B_{d}$ & o & o & + & 0 & + & 1 & + & + & 1 & & + & + & $\circ$ \\
\hline 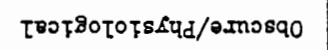 & + & 0 & + & 0 & o & $\circ$ & + & o) & 0 & & 0 & $\circ$ & $\circ$ \\
\hline 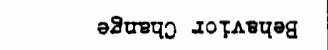 & $\rightarrow$ & - & - & $\Rightarrow$ & $\infty$ & 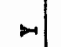 & $=1$ & $\infty$ & $m$ & $z$ & $>$ & - & $>$ \\
\hline 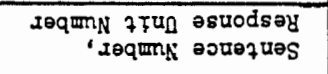 & $\cong$ & $=$ & $=$ & $\approx$ & $=$ & $\cong$ & $=$ & $\cong$ & $=$ & $\therefore$ & $\approx$ & $=$ & $\cong$ \\
\hline əsuodsey & -1 & -1 & -1 & $\rightarrow$ & $\infty$ & $\infty$ & $\rightarrow$ & $\infty$ & $\rightarrow$ & -1 & $\rightarrow$ & $\rightarrow$ & - \\
\hline sequnN Uotzseno & 0 & $n$ & $\infty$ & $\infty$ & $\sigma$ & $\sigma$ & 요 & 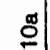 & 의 & 으 & 으 & $=$ & $\cong$ \\
\hline saqumn zuәptrodsəy & $\sim$ & $\sim$ & $\sim$ & $\sim$ & $\sim$ & s & $\sim$ & $\sim$ & $\sim$ & $\sim$ & $\sim$ & $\sim$ & $\sim$ \\
\hline 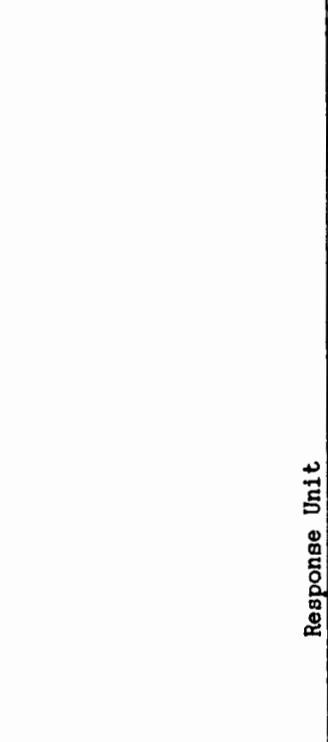 & 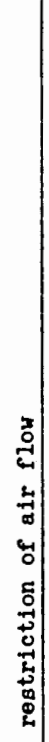 & 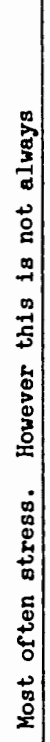 & 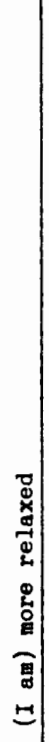 & 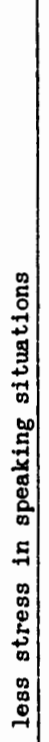 & 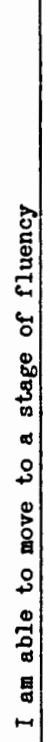 & 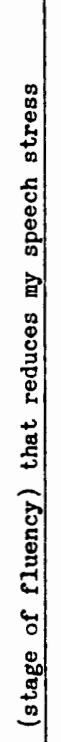 & 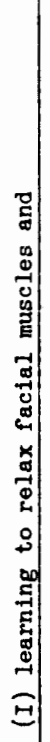 & 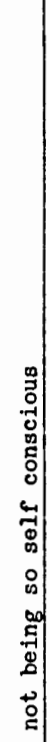 & 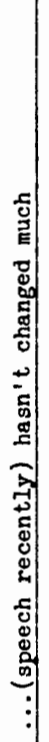 & 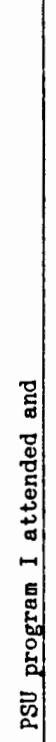 & 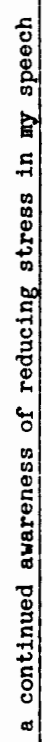 & 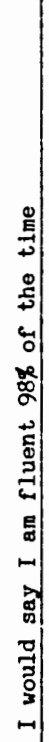 & 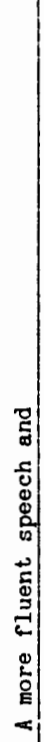 \\
\hline
\end{tabular}




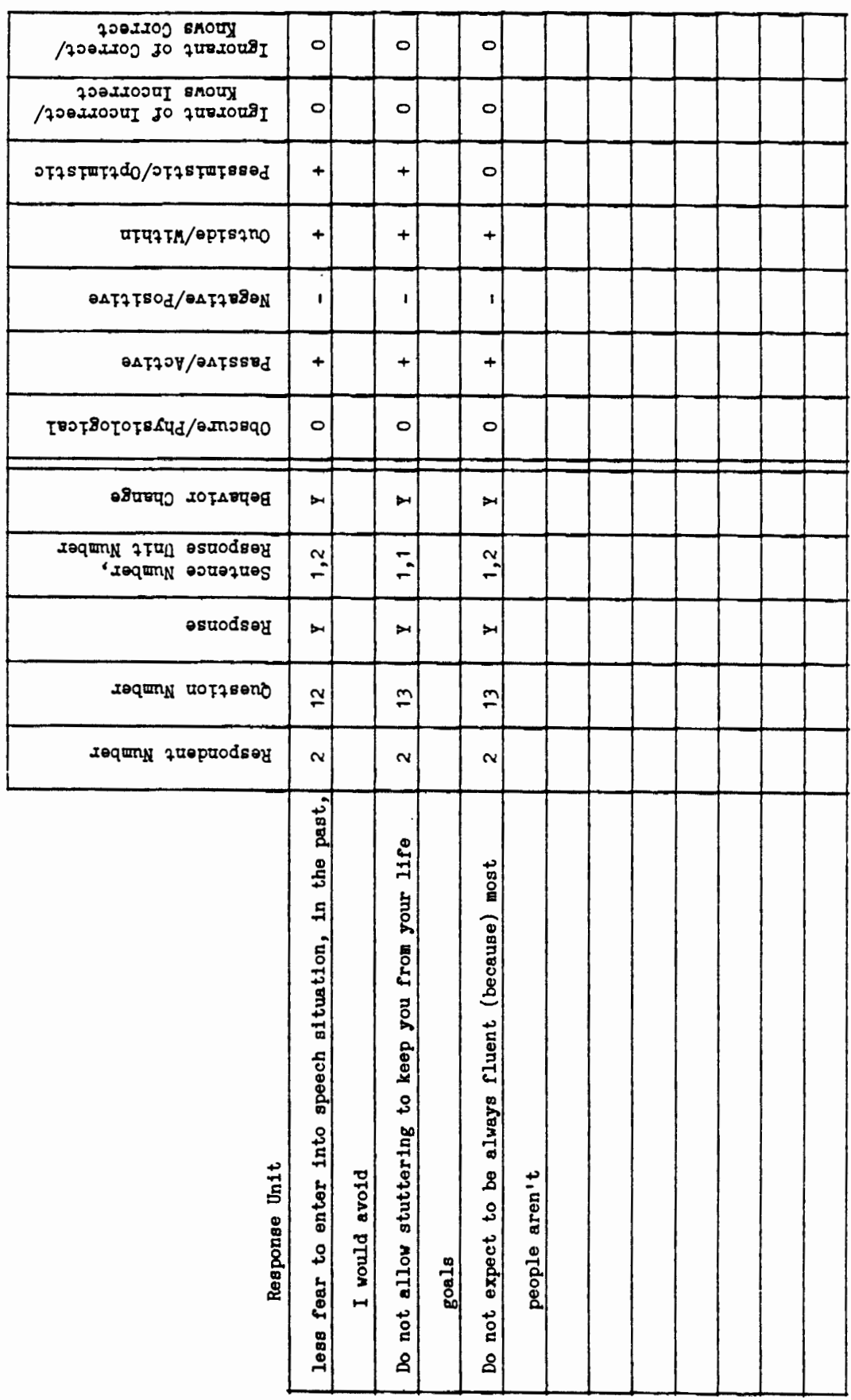


APPENDIX K

GENERAL GUIDELINES FOR LANGUAGE RESPONSE ANALYSIS

1. a. Based on a question with you stated, "I" is understood in the response even if it is not used; "I" usually indicates a judgement of WITHIN and ACTIVE (unless worded like this, Ex. "I had trouble . . ."; this indicates OUTSIDE and PASSIVE).

b. Based on a question with your stated, "my" is understood in the response even if it is not used; "my" indicates a judgement of OUTSIDE and PASSIVE.

c. Responses (regardless of question wording with you or your) that are worded in a complete and grammatical sentence with "I" or "my" included should be judged according to Noun-Verb relationship as either ACTIVE or PASSIVE and INSIDE or OUTSIDE .

d. If neither "I" nor "my" are used or can be used to make a response complete and grammatical, for example, if a person simply listed behaviors, in order not to penalize that person, a judgement of Not Applicable ( 0 ) should be made for PASSIVE/ACTIVE and OUTSIDE/WITHIN parameters.

2. If a response is PASSIVE, it is also OUTSIDE; if a response is ACTIVE, it is also WITHIN.

3. Responses with the word "have" (or some tense of):

a. "Have verb"; Ex. "I have been relaxing more." ACTIVE and WITHIN.

b. "Have something"; Ex. "I have trouble." PASSIVE, OUTSIDE and OBSCURE.

4. Fluency and stuttering should be rated Not Applicable (0) on the OBSCURE/PHYS IOLOGICAL parameter. (One exception is when the word stuttering is used as a noun; this should be judged OBSCURE.)

5. Reference to relax implies the physiological state of muscles in absence of inappropriate tension, or with appropriate tension; judge as PHYSIOLOGICAL. Other cue words include: tight, loose, tense, easy, hard, effort, less effort and sometimes stress. 
6. The following words should be judged Not Applicable (0) on the OBSCURE/PHYSIOLOGICAL and the AWARENESS (IGNORANCE/KNOWLEDGE) parameters :

$\begin{array}{lll}\text { confident } & \text { no worry } & \text { nervous } \\ \text { calm } & \text { happy } & \text { pressure } \\ \text { at ease } & \text { comfortable } & \text { stress (sometimes) } \\ \text { worry } & \text { upset } & \end{array}$

7. The referents tools, techniques, targets, stages, and others, unless they describe what they are, are judged as Not Applicable $(0)$ on the OBSCURE/PHYSIOLOGICAL and AWARENESS parameters.

8. For the OBSCURE/PHYSIOLOGICAL parameter, some general hints:

a. If physiologically descriptive, probably kNOWS CORRECT and/or INCORRECT; may be ACTIVE and WITHIN or PASSIVE and OUTSIDE.

b. If OBSCURE, or reference made to superstitious behavior, may also be IGNORANT OF INCORRECT and/or CORRECT.

c. If Not Applicable (0) due to the use of the word "stuttering" or "fluency," may have a correlate of AWARENESS:

1) If use "stuttering," may indicate KNOWLEDGE or IGNORANCE OF INCORRECT.

2) If use "fluency," may indicate KNOWLEDGE or IGNORANCE OF CORRECT.

d. If Not Applicable ( 0 ) for other reasons, the AWARENESS parameters may or may not be Applicable.

9. NEGATIVE/POSITIVE only applies to responses dealing with behaviors associated with speech or speaking situations:

NEGATIVE:

a. Not; any n't word; what one should not do.

b. Negative words associated with the "wrong" behaviors: stutter, stuttered, stuttering, dysfluent, nonfluent, tension, tensing, tense, tensed, problem, trouble.

c. "Try" paired with any n't word.

d. The words: less

decreased turn down diminished
In relation to words like: stutter, tense, relax, fluent, fear, avoidance 


\section{POSITIVE:}

a. What one should do; positive word describing "right" behavior.

b. Absence of any not, $n^{\prime} t$ words.

c. Positive words: fluent, fluently, relax, let go, loosen.

10. Any reference to just talking (indicates approach behavior), judge POSITIVE and OPTIMISTIC.

11. Any reference to knowing they have the choice to stutter or talk fluently, judge WITHIN and OPTIMISTIC.

12. If a response is in the form of comparison/contrast with a Before and After condition, the judgements for PESSIMISTIC/ OPTIMISTIC and NEGATIVE/POSITIVE must be considered (always in light of the question and of the Before condition). Cue words include :

$\begin{array}{lll}\text { but } & \text { either-or } & \text { neither-nor } \\ \text { until } & \text { or } & \text { used to/now } \\ \text { before } & \text { but } & \\ \text { for } & \text { on the contrary } & \\ \text { because } & \text { and }\end{array}$

13. Responses with the word can, always OPTIMISTIC; probab1y WITHIN also.

Responses with the word can't, always PESSIMISTIC; probably OUTSIDE also.

14. Any tendency toward fluency indicates OPTIMISTIC (above baseline); baseline or less usually indicates PESSIMISTIC. To use the PESSIMISTIC/OPTIMISTIC parameter column, then, there should be an indication of one of the following:

a. Time line or overall status (degree):

1) My fluency is good/bad (now).

2) My fluency is $98 \%$.

3) Use of cue words: more, less, so, increase, decrease, better, worse, etc.

b. Use of words can or can't.

c. Any indication of approach or avoidance behavior:

1) I talk to strangers more now. 
2) I don't like to talk to strangers.

15. Clarification of IGNORANCE parameters:

a. IGNORANCE OF INCORRECT: unaware of what one does/is doing to be dysfluent/tensed; ignorance of what they do to be incorrect or dysfluent.

Example: If I overconcentrate on my speech, I stutter.

b. IGNORANCE OF CORRECT: unaware of what one needs to do to be fluent/relaxed; ignorance of what they do to be correct or fluent.

Example: I can be fluent if I slow down.

c. Cue words or phrases:

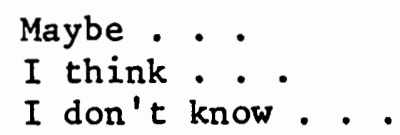

16. Reference to the following indicate IGNORANT OF CORRECT:

a. When concentrating on ... speaking fluently... I can speak fluently. When thinking about . . what I say ...

b. When speaking... slowly... I am fluent. softly... distinctly . clearly . .

(Note: Similar responses were made regarding stuttering, i.e., If I think too much about my speech, I stutter.

If I talk too fast, I stutter. These responses indicate IGNORANT OF INCORRECT.)

17. A response that physiologically describes stuttering or one of the "wrong" behaviors is NEGATIVE but it also reflects KNOWLEDGE (AWARENESS) OF INCORRECT. However, from this KNOWLEDGE OF INCORRECT, one cannot infer that the respondent also knows the CORRECT.

18. If--then or when--then statements:

If condition/situation--then action taken. When condition/situation--then action taken. The description of the action a person takes in response to a condition or situation is subject to judgement on the AWARENESS parameter(s) in light of the if (when) condition/situation.

19. "Slow down" indicates IGNORANT (or UNAWARENESS) OF CORRECT; other judgements include (+) for PASSIVE/ACTIVE and OUTSIDE/WITHIN, $(0)$ or Not Applicable) for NEGATIVE/POSITIVE, OBSCURE/PHYS IOLOGICAL, and IGNORANT OF INCORRECT/KNOWS INCORRECT. 
20. If a response has more than one response unit, be sure to analyze each response unit in light of the appropriate noun phrase. For example:

a. I tell myself to relax and let the air flow.

1) I tell myself to relax.

2) (I tell myself to) let the air flow.

b. 1) As of this date, I am not happy with my fluency.

2) It (my fluency) is acceptable in low stress situations

3) but (my fluency) bad in high stress.

21. Overall rule:

a. For responses dealing with direct speech behavior (change), all parameters should be considered when judging.

b. For responses dealing with self-concept, feelings, attitudes, life in general, etc., judge only the Attitude parameter of PESS IMIST IC/OPT IMISTIC.

22. Exclude from judgement:

a. Carrier phrases that add no meaning to the response:

First of all

For example

It may sound strange

Excuse the humor
I can put that in one sentence That is a $\$ 64$ question

All I can say is

b. Redundant statements: If a portion of a statement is repeated in a response (say the respondent is using the repetition for emphasis), only analyze it one time.

c. Responses that are from questions that were obviously misinterpreted.

d. Responses that were not requested from the question. Universally: The question determines what part or parts of the response to analyze.

e. References to Portland State Program, unless specifically requested. 
APPENDIX L

WORD CUE GUIDELINES FOR PARAMETER ANALYSIS

$\quad$ OBSCURE
It
It won't come out.
It happened
This thing
Certain things/words
Block
My tongue got stuck.
Stutering (as a noun)
Speech difficulty/
problem

PASSIVE
Noun language:
my voice...
my fluency...
Happened
Happening
Having trouble with
my...
Become (get)
It stuck in my throat.
It came out easily.
Have something
I was helped by
It...

\section{NEGATIVE}

A focus on what is
wrong with speech:

$\frac{\text { wrong with speech }}{\text { I stuttered }}$

I wasn't fluen

Negative words:
stuttering

tension

wrong behavior

Admonitions
not to do:

don't

not didn't

try not
PHYSIOLOGICAL

Any relation to use of muscles; description
what person is doing

what person is doing
with his muscles:

..relaxed my laryngeal
muscles; relaxed

$\ldots$..reduced my muscle

ension

tensed my muscles
pronounced $/ \mathrm{f} /$

too hard/easy

....stopped air with my

$\quad$ ACTIVE
Verb language:
doing
using
I verb
I am verb/verbing.
I tensed/I am relaxed/
ing
Have verb

lips 


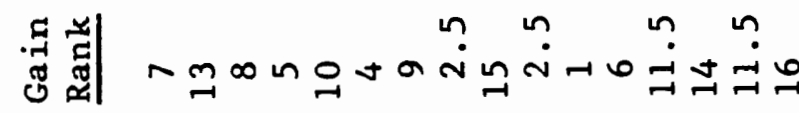

营范

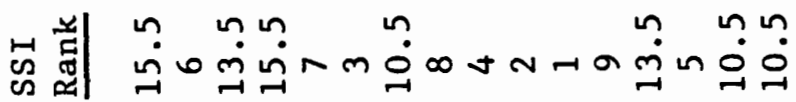

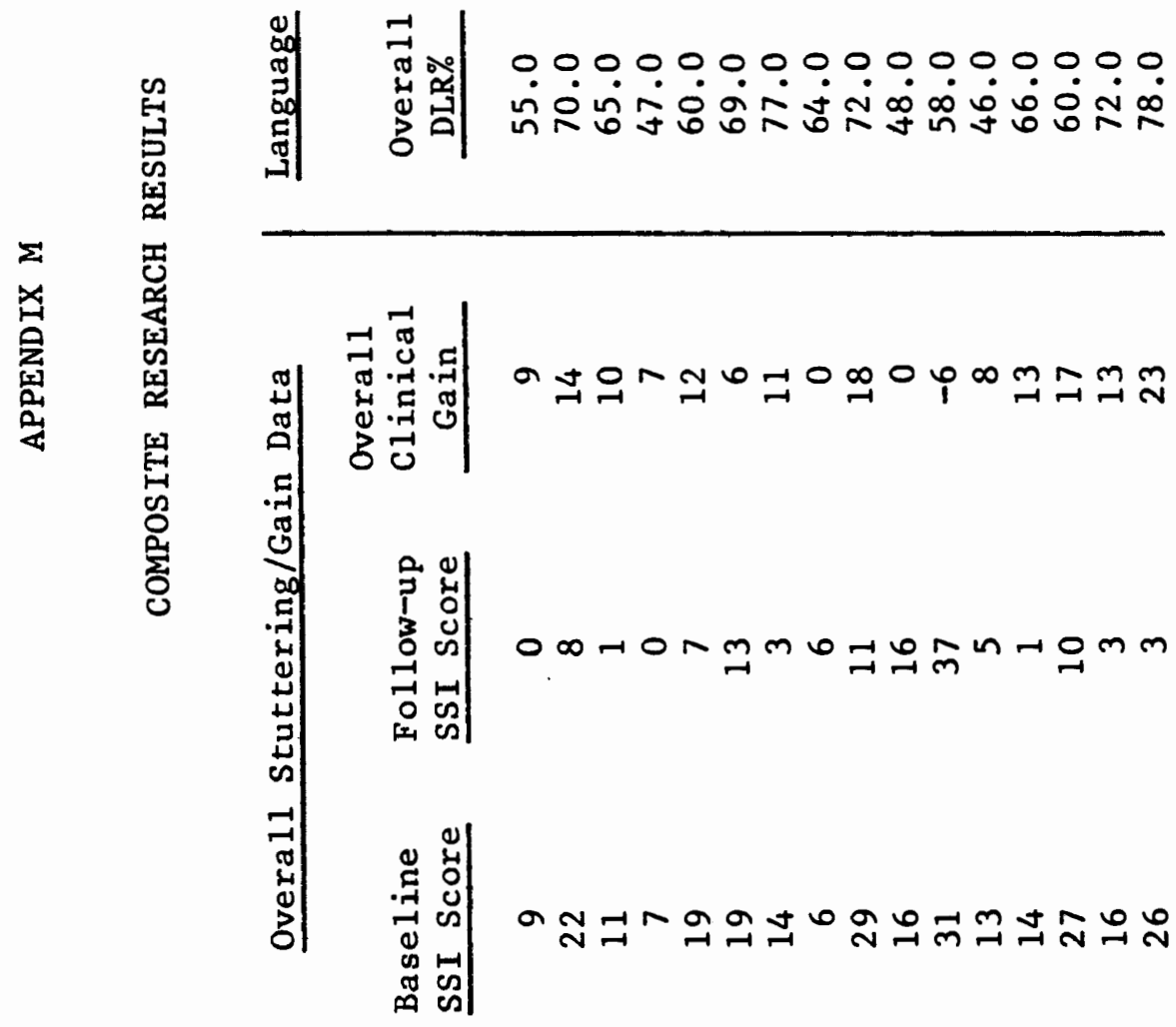

䛬 


\section{APPENDIX N}

SAMPLE QUESTIONNAIRE :

PRE- AND POST-TEST MEASURE OF LANGUAGE USAGE

\section{Pre-test (Baseline)}

1. In any situation, why do you stutter?

2. In any situation, why do you talk fluently?

3. Describe and compare how you talked five years ago/one year ago to how you talk now.

4. What do you want to gain in clinic? What are you willing to do to make those gains?

5. What can you do to improve your speech?

\section{Post-test (Follow-up)}

1. Describe what happens when you stutter.

2. Describe what happens when you talk fluently.

3. What is most helpful to you when you are talking?

4. What are the most significant benefits you have derived from professional intervention? Explain.

5. What two or three instructions do you give yourself before you start to talk? 